\title{
1 The architecture of an intrusion in magmatic mush
}

2

$3{\text { Alexandre } \text { Carrara }^{*} \text {, Alain Burgisser }}^{1}$, George W. Bergantz ${ }^{2}$

4

$5{ }^{1}$ Univ. Grenoble Alpes, Univ. Savoie Mont Blanc, CNRS, IRD, IFSTTAR, ISTerre, 38000 Grenoble, 6 France.

$7 \quad{ }^{2}$ Department of Earth and Space Sciences, Box 351310, University of Washington, Seattle, WA 98195 , 8 USA

9

10

11

12

13

14 * Corresponding author: Email: carrara.alexandre.univ@gmail.com 
Non-peer reviewed preprint submitted to EarthArXiv

\section{Abstract:}

19

20

21

22

Magmatic reservoirs located in the upper crust have been shown to result from the repeated intrusions of new magmas, and spend much of the time as a crystal-rich mush. The geometry of the intrusion of new magmas may greatly affect the thermal and compositional evolution of the reservoir. Despite advances in our understanding of the physical processes that may occur in a magmatic reservoir, the resulting architecture of the composite system remains poorly constrained. Here we performed numerical simulations using a computational fluid dynamics and discrete element method in order to illuminate the geometry and emplacement dynamics of a new intrusion into mush and the relevant physical parameters controlling it. Our results show that the geometry of the intrusion is to first order controlled by the density contrast that exists between the melt phases of the intrusion and resident mush rather than the bulk density contrast as is usually assumed. When the intruded melt is denser than the host melt, the intrusion pounds at the base of the mush and emplaced as a horizontal layer. The occurrence of RayleighTaylor instability leading to the rapid ascent of the intruded material through the mush was observed when the intruded melt was lighter than the host one and was also unrelated to the bulk density contrast as considered before. In the absence of density contrasts between the two melt phases, the intrusion may fluidize the host crystal network and slowly ascend through the mush. The effect of the viscosity contrast between the intruded and host materials was found to have a lesser importance on the architecture of intrusions in a mush. Analyzing the eruptive sequence of well documented eruptions involving an intrusion as the trigger shows a good agreement with our 
38 modeling results, highlighting the importance of specifically considering granular dynamics when 39 evaluating magmas and mush physical processes.

40 Keywords: Mush, Magma, Intrusion, Density contrast, CDF-DEM, Granular mechanics. 
Non-peer reviewed preprint submitted to EarthArXiv

\section{Introduction:}

43

44

45

46

47

48

49

50

51

52

53

54

55

56

57

58

59

60

61

62

Evidence for injections of new magmas, also called recharge events, are ubiquitous in magmatic systems (Wiebe, 2016). They are inferred to cause the formation of long-lived, supersolidus magmatic reservoirs located in the upper crust (e.g. Annen et al., 2015, 2006; Dufek and Bergantz, 2005; Karakas et al., 2017). Together with the thermal structure of the upper crust and the frequency of recharge, the geometry and mode of emplacement of the intruded magma was also identified as having a crucial effect on the long-term evolution of igneous bodies (Annen et al., 2015). Diverse evidence supports the view that magmatic reservoirs reside most time in a mush state that is frequently disturbed by injection of new magmas (e.g. Bachmann and Huber, 2016; Cashman et al., 2017, and reference therein). A magmatic mush is a crystal-rich magma in which crystals are in close and sometimes frictional contacts, forming a semi-rigid framework where stress is transmitted by force chains (Bergantz et al., 2017). As a result, mushes transition between crystal-rich suspensions to a 'lock-up' state that inhibits the ability of the magma to erupt.

The injection of hotter magma into a cooler host has been suggested as a means to trigger volcanic eruptions (e.g. Caricchi et al., 2014) and the intrusion style plays a fundamental role in the way mush rejuvenates (process of recycling the mush to generate an eruptible magma) prior to eruption (Parmigiani et al., 2014, and references therein). Several scenarios assume that the intruder is emplaced as sills at the base of the mush, and rejuvenate it by supplying heat but no mass except possibly exsolved volatiles (Bachmann and Bergantz, 2006; Bergantz, 1989; Burgisser and Bergantz, 2011; Couch et al., 2001; Huber et al., 2011). Other scenarios consider 
64 that the injected magma may penetrate the mush, producing various degrees of mixing with the 65 resident mush depending on its buoyant acceleration (e.g. Bergantz and Breidenthal, 2001; 66 Koyaguchi and Kaneko, 2000; Weinberg and Leitch, 1998). Whether an intrusion generates 67 extensive mass transfer, or is limited to thermal exchanges between an underplated intruder and a 68 host mush is thus a key element shaping the outcome of open-system events. A major obstacle to 69 our current understanding of the formation and evolution of igneous bodies is that little is known 70 about the architecture of intrusions and controlling physical parameters. performed with pure fluids mimicking the bulk physical properties (density and viscosity) of the magmas (e.g. Huppert et al., 1986; Jellinek and Kerr, 1999; Snyder and Tait, 1995). Mush dynamics, however, differs from that of pure fluids because of the complex rheological feedbacks 75 between melt and crystals. An essential physical process is that melt and crystals may experience relative motions. Numerical simulations explicitly accounting for such decoupled motions as well 77 as the building and destruction of force chains between crystals (Bergantz et al., 2015; Schleicher 78 et al., 2016; Schleicher and Bergantz, 2017) have revealed that the local injection of pure melt of 79 the same density and viscosity as the mush interstitial melt easily fluidizes, penetrates, and 80 partially mixes with the overlying mush if it is sufficiently vigorous. This local unlocking of a mush suggests that the conditions of efficient mass transfer and mixing are easier to achieve than 82 previously thought. Conversely, it is adding constraints on rejuvenation scenarios based on the 83 emplacement of an underlying mafic gravity current (e.g. Bachmann and Bergantz, 2006; 
84 Burgisser and Bergantz, 2011) by suggesting that underplating may require contrasts in densities 85 and/or viscosities to hinder fluidization.

86 Our capacity to interpret the various natural expressions of open-system events, such as 87 eruptive products containing both the intruded magma and the resident mush, is hindered by our 88 partial understanding of the architectural end-members of these events, such as fluidization or 89 underplating. To characterize the geometry and emplacement styles of intrusion events into a 90 residing mush, we performed numerical simulations using a combination of fluid mechanics and 91 discrete elements (Bergantz et al., 2015; Schleicher et al., 2016; Schleicher and Bergantz, 2017) .

92 As the dissimilarities between the density and viscosity of the two melts require special attention 93 to better characterize the end-member cases of open-system events, we explored how these 94 parameters condition the dynamics of the intruded material when injected into a mush. We first 95 introduce the numerical model and the dimensionless parameters controlling recharge dynamics 96 that are varied in the simulations. Results of numerical simulations involving magmas of 97 contrasted physical properties are then presented in the framework of the dimensionless 98 parameters. Finally, we relate our results to well-documented cases of eruptions triggered by an 99 intrusion event.

\section{2: Method}

In order to characterize the geometry and emplacement mechanism of intrusion in mush accounting for granular dynamics, we performed Computational-Fluid-Dynamic and Discrete- 
104 Element-Method (CFD-DEM) numerical simulations by using the MFIX-DEM software (https:// 105 mfix.netl.doe.gov/). Details about the theory and implementation of the model can be found in 106 Garg et al. (2012), Syamlal (1998), Syamlal et al. (1993), and validation of the DEM approaches 107 in Garg et al. (2012) and Li et al. (2012) (see supplementary information 1 for a list of the 108 equations we used). To ensure stability and efficiency of the simulations, we used the composite 109 implicit force, which includes gravitational, pressure and drag forces, proposed by Burgisser et al. 110 (in review) instead of the usual numerical forces evaluations (Garg et al., 2012). The composite 111 force expression do not requires the use of time steps shorter than the characteristic durations of 112 the hydrodynamic processes accounted. As a result, the viscosity of the melt phases may be 113 increased without decreasing the simulation time step compared to that required to ensure the 114 stability of a dry (zero viscosity) granular simulations.

The computational domain is a $3 \mathrm{D}$ medium of $1.6 \times 0.8 \times 0.05 \mathrm{~m}$ (length $\times$ height $\times$

116

117

118 width) filled with a resident mush (Fig. 1). This geometry also allowed us to populate the mush with mm-size particles, thereby ensuring a 1:1 scale compared to nature. We will show a posteriori that our particle bed behaves identically to a bed twice as thick (Bergantz et al., 2015). Our runs are thus representative of an open system event despite the small size of the domain compared to a natural system We used such geometry instead of a two dimensional one to ensure that the build-up and breaking of force chains have a sufficient degree of freedom in space to replicate best the mechanics of the granular phase. We created a mush layer of $\sim 0.3 \mathrm{~m}$ height with an initial crystal content of $\sim 0.64$ by simulating the settling of the particles in a vacuum and positioning them at the base of the domain. We used the same density for all particles $\left(\rho_{p}=3300\right.$ 
Non-peer reviewed preprint submitted to EarthArXiv

$125 \mathrm{~kg} \mathrm{~m}^{-3}$ ) and three different diameters $(4.5,5$, and $5.5 \mathrm{~mm})$ to avoid artificial clustering. All 126 simulations use the same initial particle bed. A crystal-free magma is injected at the base of the 127 mush layer with a superficial vertical velocity, $U_{i n j}$, through an inlet having a width, $W_{i n j}$. The 128 density and the viscosity of the injected melt are kept constant between all the simulations ( $129 \rho_{i}=2500 \mathrm{~kg} \mathrm{~m}^{-3} ; \eta_{i}=1 \mathrm{~Pa} \mathrm{~s}$, see table 2 for the list of the parameters kept constant). We used a 130 conduit of $3.2 \mathrm{~cm}$ in height to supply the inlet to ensure that the intruder enters the mush as a 131 Poiseuille flow. At the top of the domain, we used a pressure outflow boundary conditions to 132 ensure the overall mass conservation within the entire domain, which is consistent with an open133 system event. The boundary conditions at the front and back of the domain are cyclical, which 134 means that the intruder corresponds to a dyke having one infinite dimension. All the other 135 boundary conditions are non-slip walls (Fig 1). To maintain constant values of melt density and 136 viscosity during the runs (and hence constant density and viscosity contrasts), thermal effects are 137 ignored. This is consistent with the small dimensions of the computational domain that ensure run 138 times shorter than those allowing significant heat exchanges.

139 We performed simulations by varying the density and viscosity of the host melt. In order 140 to compare simulations, we used dimensionless quantities to scale the effects of the contrasts in 141 densities and viscosities, and injection velocities. The injection velocity and melt viscosity 142 control the stress applied by the input of new materials to the mush. These parameters enter the 143 minimum fluidization velocity, $U_{m f}$ (Schleicher et al., 2016, see supplementary information 2 for 144 derivation of $U_{m f}$ ), which expresses the minimum superficial velocity required for the injection to 145 entrain the host solids and generate the fluidization of the particle bed. As the injected melt 
146 differs from the host melt, two minimum fluidization velocities can be calculated depending on

147 which melt is considered. For all simulations, we used the minimum of these two velocities,

148 which here always corresponds to that using the host melt properties. The dimensionless injection

149 velocity, $U^{*}$, is defined as:

150

$$
U^{*}=\frac{U_{i n j}}{U_{m f}} .
$$

151 In simulations having identical $U^{*}$, the injection imposes the same stress to the overlying mush.

152 However, the time needed to inject the same new melt volume changes between simulations

153 because $U_{m f}$ varies. We thus used a dimensionless time, $t^{*}$, to scale the simulation time (Bergantz

154 et al., 2017):

155

$$
t^{*}=\frac{t U_{i n j}}{H_{b e d}}
$$

156

157

161 buoyancies may be defined. The first one, $\rho^{*}$, expresses the buoyancy contrast between the two 162 melts:

163

$$
\rho^{*}=\frac{\rho_{i}-\rho_{h}}{\rho_{i}},
$$


164 where $\rho_{i}$ is the density of the intruded melt, and $\rho_{h}$ is the host melt density. The second one, $\rho_{b}^{*}$,

165 takes the presence of crystals in the host material into account and scales the bulk densities:

166

$$
\rho_{b}^{*}=\frac{\rho_{i}-\left(\rho_{h}(1-\Phi)+\rho_{p} \Phi\right)}{\rho_{i}},
$$

167 where $\rho_{p}$ is the density of the host solids, and $\Phi$ is the particle volume fraction. The viscosity

168 contrast, $\eta^{*}$, between the two melts is expressed as:

169

$$
\eta^{*}=\frac{\eta_{h}}{\eta_{i}}
$$

where $\eta_{h}$ is the host dynamic viscosity and $\eta_{i}$ is that of the injected melt.

\section{3: Results}

We performed 25 numerical simulations to explore the influence of the host melt density 174 and viscosity (See Table 3 for a list of all the simulations and corresponding parameters). For 175 these simulations, the injection velocities are such that the ratio with the respective minimum 176 fluidization velocity, $U^{*}$, remains constant at $U^{*}=21.2$. This ratio is chosen to match that used

177 previously in similar works (Schleicher et al., 2016; Schleicher and Bergantz, 2017) according to

178 the formula presented in the supplementary material 2 . We performed an additional 4 simulations

179 at higher injection velocities to explore the effect of $U^{*}$ on intrusion dynamics. 


\section{Non-peer reviewed preprint submitted to EarthArXiv}

180

181

182

183

184

185

186

187

188

189

190

191

192

193

194

195

196

197

198

199

Figure 2 plots the simulations at the lowest $U^{*}, 21.2$, as functions of the dimensionless

quantities $\rho^{*}, \rho_{b}^{*}$, and $\eta^{*}$. It shows that the intrusions can be classified in three regimes as a function of the reduced buoyancy between the two melts, $\rho^{*}$. When $\rho_{i}=\rho_{h}$, the fluidization regime is observed. If $\rho_{i}>\rho_{h}$, the spreading regime occurs, whereas if $\rho_{i}<\rho_{h}$, the rising regime occurs (see next paragraph for a detailed description of the regime dynamics). The bulk density contrast $\rho_{b}^{*}$ is always negative and the regime transition occurs at a value $(-0.2025)$ of no particular physical significance. The three regimes do no depend on the viscosity contrast $\eta^{*}$.

The fluidization regime was observed in the simulations once $\rho_{i}=\rho_{h}$, and consists in the development of a fluidized area above the inlet in which the intruded melt rises through the mush (Fig. 3A-C), as described previously (Bergantz et al., 2015; Schleicher et al., 2016). The fluidization of the mush is initiated by the dilation of the crystal framework to crystal volume fraction below 0.3 above the inlet that locally destabilizes the forces chains network that supports the bed and separates the crystals in contact. The fluidized volume grows vertically above the inlet because of two mechanisms. The first is the upward entrainment of the particles localized above the fluidized cavity, which results in bulging the top surface of the mush layer (Fig. 3AC). The second mechanism is the progressive erosion of the crystals jammed at the boundary between the mush and the fluidized volume. Once separated, crystals start settling in the fluidized area because of this process of mush erosion, causing the fluidized area to ascend faster than the intruded melt (green outline in Fig 3A-C). The intruder flows mainly vertically with a minor lateral porous flow. When the fluidized cavity reaches the top of the particle bed, its width 
progressively decreases to stabilize in the shape of a vertical chimney. At steady state, when $t^{*}>1$,

201 the crystals located within the chimney show both upward and downward motions whereas the ones located around the chimney flow slowly in the direction of the inlet, forming a "mixing bowl' as a whole, fully recovering the dynamics first described in Bergantz et al. (2015).

The spreading regime, which prevails in simulations once $\rho_{i}>\rho_{h}$, is characterized by the lateral spreading of the injected melt similarly to a gravity current hugging the floor of the host reservoir (Fig. 3D-F). The main difference with a pure fluid gravity current is that the melt is progressively flowing across the mush as permeable flow. At the start of the injection, the crystal framework experienced a dilation, which initiates host crystals settling in the same fashion as in the fluidization regime. The lateral flow of the intruded melt is able to laterally entrain the host crystals, creating two counter rotating granular vortexes in the residing mush with downward motions above the inlet (Fig. 3D-F). Such granular vorticity affects the flow pattern of the fluid in the mush. The fluidized volume grows either predominantly laterally or vertically, depending on the relative importance between the lateral entrainment of the host solids by the intruder and the vertical settling of the mush crystals. As the lateral propagation of the intruder progresses, so does the size of the two granular vortexes, making this style of intrusion affect a larger mush volume than the fluidization regime.

The rising regime (Fig. 3G-I), is characterized by the ascent of the intruded melt within the mush that occurred in simulations once $\rho_{i}<\rho_{h}$. Runs start with the initial growth above the inlet of a cavity filled with the intruded fluid. The cavity becomes gravitationally unstable and ascends within the mush, forming a Rayleigh-Taylor instability. The ascent of the intruder 
221 continues above the particle bed, entraining solids from the host. The instability is driven by its

222 head because of the buoyant batch of intruded melt. This driving batch is surrounded by a volume 223 of fluidized host mush (Fig. 3G-I). The dimensionless time at which the intrusion reaches the 224 mush top $\left(t^{*} \sim 0.3\right)$ is shorter than that of the two other regimes because the Rayleigh-Taylor 225 instability significantly accelerates the transport of the intruder.

Figure 2 suggests that the viscosity contrast does not control the end-member shape of the

227 228

intruder flow. Larger viscosity contrasts, however, increase the trends of some aspects of mush dynamics. Figure 3 illustrates how viscosity bears on flow patterns.

In the fluidization regime, the increase of the host viscosity enhances the formation of crystal-poor batches at the top of the intruded volume (Fig. 3A-C). Because the minimum fluidization velocity within the intruded melt is lower than for the host, the crystals are not fluidized and sediment in the intruded melt to accumulate atop the inlet (Fig 3B-C). Because we defined $t^{*}$ to scale the dynamics of the mush, the increase of the host melt viscosity decreases the injection velocity and the duration, $t$, required to reach the dimensionless time $t^{*}=1$. As a result, increasing melt viscosity increases the ability for the intruded melt to experience lateral porous flow through the host crystal frameworks (Fig. 3B-C). It also lengthens the time span for a crystal to settle over the same characteristic distance between the intruded and host melts, which results in the formation of the crystal poor volume at the top of the intruded volume (Fig. 3B-C). The increase in the host melt viscosity, however, does not affect the volume of mush showing a decrease in crystal volume faction and a distortion of the force chains. 
242 intruder and the entrainment of the host crystals in the two counter rotating vortexes (Fig 3E-F).

243 Large host melt viscosity causes the lateral entrainment of the solids to be more efficient than 244 particle settling, which results in the elongation of the fluidized volume in the horizontal 245 direction. In the same fashion as in the fluidization regime, the lower superficial injection rate 246 enhances the ability of the lateral porous flow of the intruder. This effect is expressed by the 247 decrease of the thickness of the intruded layer with the increase of the host viscosity (Fig 3D-F). 248 It results that reaching the same volume of mush entrained by the intrusion requires less intruded 249 material as the viscosity of the host melt increases.

In the rising regime, increasing the viscosity contrast enlarges the vortexes sizes and the

251

252 253 separation distance between their centers (Fig 3G-I). The dimensionless time, $t^{*}$, at which the intruder instability occurs decreases with the viscosity of the host. The volume of the intruded melt driving the Rayleigh-Taylor instabilities is lower when a viscosity contrast exists. When a viscosity contrast is present, the volume of the intruded driving the instability does not vary significantly (Fig 3H-I). The larger volume of the intruder driving the Rayleigh-Taylor instability can be addressed by the ratio between the dimensional injection rate and Rayleigh-Taylor growing rate. In Fig. $3 \mathrm{G}$, this ratio is higher than in Fig $3 \mathrm{H}-\mathrm{I}$, and a significant volume of fluid is injected during the growth and entrainment of the instability. On the contrary, in Fig 3H-I, this ratio is sufficiently small so that the amount of melt injected during the growth of the instability is negligible compared to the volume required to initiate it. However, the volume of the mush 


\section{Non-peer reviewed preprint submitted to EarthArXiv}

261 remobilized by the intruder flow does not significantly vary with the host melt viscosity (Fig. $2623 \mathrm{G}-\mathrm{I})$.

The additional 4 simulations in the spreading regime suggest that buoyancy effects

264

265

266

267

268

269

270

271

272

273

274

275

276

277

278

279

280

dominate the intruder flow up to $U^{*} \simeq 10^{5}$. Figure 4 shows the temporal evolution of the height reached by the intruded volume, $H^{*}$, as a function of injection rate. All injections grow purely vertically at first $\left(t^{*} \leq 0.1\right)$. As seen above, at the low injection rate of 21.2 , the intrusion stalls rapidly and spreads laterally (simulation A25, Fig. 4). Increasing the injection rate causes stalling to occur later and higher. When $t^{*}>0.2$, injection growth switches from vertical to radial. When $U^{*}>10^{5}$, the behavior of the intruder is dominated by the injection rate, which causes the radially growing intrusion to reach the top of the bed at $H^{*}=1$. Despite that all simulations have the same intruder shape before stalling, the size of the region surrounding the intruder that is affected by dilatancy increases with $U^{*}$. The highest injection rate (simulation B4 with $U^{*}=10^{6}$ ) strictly follows the theoretical curve for a radial growth and reaches $H^{*}=1$ at $t^{*} \approx 2.5$, as predicted by geometrical arguments (supplementary information 3).

The decoupling between the motions of the two phases results from processes unique to granular mechanics that our discrete numerical model is able to capture. Mush dilation is key for permeable melt flow to occur. The initiation of the intrusion increases the pore pressure in the mush around the inlet (Fig. 5A). This overpressure progressively propagates outwards and decreases the crystal volume fraction in the overlying mush (Fig. 5B). As the intrusion propagates, the effect of the overpressure is supplemented with the Reynolds dilatancy generated 
281 by the granular vortexes in the mush (Fig 5C). The dilation of the solid framework increases its 282 permeability of the solid framework and in turn the possibility of relative motion between the 283 crystals and the interstitial melt (Fig. 5C). This phenomenon is particularly clear in the case of the 284 rising regime. The intruder is surrounded by a volume of mush that underwent such dilation that 285 it is in the dilute regime. The contact region between the two magmas is dominated by melt-melt 286 interface interspersed with isolated crystals. As a result, entrainment is ruled by melt vorticity.

287 Efficient entrainment of two fluids with a viscosity contrast occurs only when the most viscous 288 fluid bears large levels of vorticity (Jellinek and Kerr, 1999). In our runs, the intruder melt 289 viscosity is equal or less than that of the host, and the vorticity is concentrated close to or inside 290 the intrusion (Fig. S4 in the supplementary information 4). This situation yields the weak 291 entrainment observed in the rising regime and the transition from vertical growth to spreading of 292 the intrusion melt as injection velocity decreases (Fig. 4). The concept of bulk reduced buoyancy 293 thus fails to predict the intrusion geometry for two reasons. First, it assumes the absence of 294 relative motion and thus ignores the transfer of crystals from host to intrusion. Second, in cases 295 when sufficient mush dilation occurs, entrainment is controlled by the melt-melt interface and 296 the associated density and viscosity contrasts. The interplay between pore pressure, dilation, melt 297 interface dynamics, and permeable flow controls the transport of mass within our modeled 298 magmatic reservoir.

\section{4: Comparison with natural systems} physical parameters of 15 eruptions involving the intrusion of new magma (Table S3-S4 in the 


\section{Non-peer reviewed preprint submitted to EarthArXiv}

302 supplementary information 5). All host magmas are mushes but for a few cases that either have

303 crystal gradients in their reservoirs (Krakatau), or for which there is ambiguity on the respective

304 roles of the intruder and host magmas (Unzen, Minoan, and Katmai-Novarupta). In the studies

305 surveyed, melt viscosity and melt density of host magmas were most often directly determined

306 from eruptive products and pre-eruptive conditions such as pressure, temperature, and melt water

307 content (details on how parameters were obtained are in Table S3-S4 (see supplementary 308 information 5)).

The cases are organized into three categories depending on the observed eruptive sequence. In the first category, the intruder was erupted first, followed by the emission of host magma or a mixture of host and intruder. This category implies that the intruder magma was able

312 to efficiently penetrate and pass through the host magma. In the second category, both host and intruder magmas were erupted simultaneously, with the intruder most often forming enclaves or mingling structures. The last category feature cases where the mixing was so thorough that the eruptive products only bear cryptic traces of the intruder, such as isolated intruder crystals floating in the host or crystal disequilibrium textures.

Figure 6A shows the ratios of bulk viscosities and bulk densities between the intruder magma and the host magma(s) for the 15 eruptions. Figure 6A contains two physically meaningful thresholds, that of neutral buoyancy at the bulk density ratio of 0 and that of equal viscosity at the bulk viscosity ratio of one. The three types of eruptive sequence are not sorted following any of these thresholds. Figure $6 \mathrm{~B}$ shows the same eruptions plotted as functions of melt properties instead of bulk properties. Our numerical runs cover the full range of natural 
Non-peer reviewed preprint submitted to EarthArXiv

323 density ratios and a more restricted range of viscosity ratios (from 1 to $10^{2} \mathrm{vs}$. $10^{-1}$ to $<10^{4}$ in

324 nature). Figure 6B also shows the dividing line between rising and spreading dynamics at the

325 level of neutral buoyancy with respect to the melts. With the possible exception of two cases (see

326 Discussion), the Minoan eruption and the 1912 Katmai-Novarupta eruption, the rising regime is

327 populated by the eruptions that first ejected intruder material. This divide between cases where at 328 least some of the intruder magma had the capacity to go unscathed through the host and cases 329 where none of it escaped from host interaction is consistent with our numerical results.

330 
Non-peer reviewed preprint submitted to EarthArXiv

344 interface (Fig. 5C). This sheds light on the importance of granular mechanisms such as pore 345 pressure, dilatancy and permeable flow in shaping the end-member cases of mush intrusion.

We characterized the parameter ranges of a series of well-documented cases of eruptions

347 that features magma mixing, focusing on the densities and viscosities of the two end-member

348 magmas involved and on the order of the eruptive sequence. Two cases, Katmai and the Minoan

349 eruption, straddle two eruptive sequence categories because the intruders may have been

350 transported alongside (as opposed to through) the host magmas. Both cases are close to the

351 neutral buoyancy level, regardless of the scenario considered (Fig. 6B). Importantly, each

352 individual scenario is consistent with our regimes. The Katmai eruption first emitted rhyolite. The

353 Katmai scenario corresponding to a rhyolite intruding a more mafic host (Eichelberger and

354 Izbekov, 2000) is consistent with it being located in the rising regime. In the other scenario

355 (Singer et al., 2016), the rhyolite is part of the host reservoir, which is consistent with that

356 scenario being in the spreading regime. The Minoan scenario located in the rising regime

357 (Cadoux et al., 2014) would have indeed emitted the intruder first, but it feature a host filled by

358 low-crystallinity magma, which is at odds with our hypothesis that the host is in a mush state.

359 The other Minoan scenario (Druitt, 2014; Flaherty et al., 2018; Martin et al., 2010) involves a

360 mushy host compatible with this hypothesis and is consistent with the spreading regime that

361 hinders first emission of the intruder. The overall good agreement between the observed eruptive

362 sequences and our numerical results (Fig. 6B) constitutes a serious argument in favor of the fact

363 that open-system events are, to first order, controlled by the density contrast between the melt 
364 phases of the intrusion and mush. It also suggests that injection momentum was quickly 365 exhausted, letting buoyancy control the unfolding of the event.

Two special natural cases can be added to the comparison between our dynamics regime

367

368

369

370

371

372

373

374

375

376

377

378

379

380

381

382

383

384

and natural data (Fig. 6B). The first is the 1883 eruption of Krakatau volcano (Mandeville et al., 1996), which resulted from remobilization by basaltic intruder of a stratified magma chamber featuring three compositions, none of them being in a mush state (andesite, dacite, and rhyodacite). Evidence that the basalt intruder was erupted first comes from basaltic ashes collected during the first phase of the eruption (Self, 1992). The presence of several magmas in the host reservoir, however spatially distributed, causes a large uncertainty in the host properties. As a result, the Krakatau eruption spans the divide between the regimes established by our simulations (Fig. 6B). It is thus an inconclusive case where the intruder was erupted first. The second natural case is the 1991-1995 eruption of Unzen volcano, for which the intruder could have been either andesitic (Holtz et al., 2004), or basaltic (Browne et al., 2006). Regardless of its composition, the intrusion caused thorough mixing and the first magma erupted was the product of this mixing. If the intruder was basaltic, it was buoyant with respect to the felsic host and if it was andesitic, it was denser that the host. As a result, Unzen spans the divide between the rising and spreading regime (Fig. 6B). Considering that the intruder input was large ( $>30 \mathrm{wt} \%$ of the eruptive products; Holtz et al., 2005), and if any credit is given to our inferences, the intruder was more likely to be andesitic than basaltic because this latter composition would have been prone to preserve its integrity while going through the host mush, erupting first. 


\section{6: Conclusions}

This study highlights the importance of granular mechanics in mush processes, which

387 388 389

390

391

392

393

394

395

396

397

398

399

400

401

402

403

404

differ significantly from ones expected with purely fluid models. As expected, our simulations show that when the injection velocity is high $\left(U^{*}>10^{5}\right)$, intrusion dynamics is dominated by the injection momentum and the intruded cavities grow radially. When the injection velocity is below this threshold, however, buoyancy controls the behavior of the intruder in an unexpected way. Bulk buoyancy contrasts appear to play no role in the way the intruder flows. Instead, the density contrast between the host and intruded melts exerts a first-order control on the architecture of an intrusion event in a mush. When the two melt densities are identical, the intruder fluidizes the mush and creates a mixing bowl, as described in Bergantz et al. (2015). When the intruded melt is lighter than that of the host, it rises through the mush. Mush dilation around the intruder causes the contact region between the two magmas to be dominated by melt-melt interface interspersed with isolated crystals. Entrainment in this rising regime is ruled by the amount of vorticity of the most viscous melt. As our in our runs the intruder melt viscosity was equal or lower than that of the host, no entrainment was observed. Intruder melts denser than the host spread laterally partly as permeable flows through the host mush. The lateral spreading of the intruder generates two counter rotating granular vortexes with downward motions above the inlet, which maximizes the volume of the mush entrained by the gravity current. In this spreading regime, the combined effects of the initial pore overpressure at the inlet and the Reynolds dilatancy resulting from the lateral spreading of the intruder are able to fluidize the overlying mush. 
Non-peer reviewed preprint submitted to EarthArXiv

405

406

407

408

409

410

411

412

413

414

415

416

417

418

419

420

421

422

423

424

425

426

427

428

We tested whether the first-order effect of melt density contrast was expressed in nature. We tallied 15 well-documented eruptive sequences, classifying them according to the expected outcomes of the three dynamic regimes we defined. We found overall good agreement between eruption sequences and our model predictions, which suggests that granular mechanisms such as pore pressure, dilatancy, and permeable flow play a fundamental role in the unfolding of opensystem events. Granular dynamics and the decoupling of melt and crystals are thus key in shaping reservoir and volcanic processes.

\section{Acknowledgments:}

All the numerical simulations presented in this paper were performed using the CIMENT infrastructure (https://ciment.ujf-grenoble.fr), which is supported by the Rhône-Alpes region (GRANT CPER07_13 CIRA: http://www.ci-ra.org). G.W.B. was supported by National Science Foundation grants DGE-1256068, EAR-1049884 and EAR-1447266. Authors declare no conflicts of interest.

\section{References:}

Annen, C., Blundy, J.D., Leuthold, J., Sparks, R.S.J., 2015. Construction and evolution of igneous bodies: Towards an integrated perspective of crustal magmatism. Lithos 230, 206-221. https://doi.org/10.1016/j.lithos.2015.05.008

Annen, C., Blundy, J.D., Sparks, R.S.J., 2006. The Genesis of Intermediate and Silicic Magmas in Deep Crustal Hot Zones. J Petrology 47, 505-539. https://doi.org/10.1093/petrology/egi084

Bachmann, O., Bergantz, G.W., 2006. Gas percolation in upper-crustal silicic crystal mushes as a mechanism for upward heat advection and rejuvenation of near-solidus magma bodies. Journal of Volcanology and Geothermal Research 149, 85-102. https://doi.org/10.1016/j.jvolgeores.2005.06.002 
Non-peer reviewed preprint submitted to EarthArXiv

Bachmann, O., Huber, C., 2016. Silicic magma reservoirs in the Earth's crust. American Mineralogist 101, 2377-2404. https://doi.org/10.2138/am-2016-5675

Barth, A., Edmonds, M., Woods, A., 2019. Valve-like dynamics of gas flow through a packed crystal mush and cyclic strombolian explosions. Sci Rep 9, 1-9. https://doi.org/10.1038/s41598-01837013-8

Bergantz, G.W., 1989. Underplating and Partial Melting: Implications for Melt Generation and Extraction. Science 245, 1093-1095. https://doi.org/10.1126/science.245.4922.1093

Bergantz, G.W., Breidenthal, R.E., 2001. Non-stationary entrainment and tunneling eruptions: A dynamic link between eruption processes and magma mixing. Geophysical Research Letters 28, 30753078. https://doi.org/10.1029/2001GL013304

Bergantz, G.W., Schleicher, J.M., Burgisser, A., 2017. On the kinematics and dynamics of crystal-rich systems. J. Geophys. Res. Solid Earth 122, 2017JB014218. https://doi.org/10.1002/2017JB014218

Bergantz, G.W., Schleicher, J.M., Burgisser, A., 2015. Open-system dynamics and mixing in magma mushes. Nature Geosci 8, 793-796. https://doi.org/10.1038/ngeo2534

Browne, B.L., Eichelberger, J.C., Patino, L.C., Vogel, T.A., Uto, K., Hoshizumi, H., 2006. Magma mingling as indicated by texture and $\mathrm{Sr} / \mathrm{Ba}$ ratios of plagioclase phenocrysts from Unzen volcano, SW Japan. Journal of Volcanology and Geothermal Research, Modern Trends in Petrography: 154, 103-116. https://doi.org/10.1016/j.jvolgeores.2005.09.022

Burgisser, A., Bergantz, G.W., 2011. A rapid mechanism to remobilize and homogenize highly crystalline magma bodies. Nature 471, 212-215. https://doi.org/10.1038/nature09799

Burgisser, A., Carrara, A., Annen, C., in review. Numerical simulations of magmatic enclave deformation. Journal of Volcanology and Geothermal Research (submitted).

Cadoux, A., Scaillet, B., Druitt, T.H., Deloule, E., 2014. Magma Storage Conditions of Large Plinian Eruptions of Santorini Volcano (Greece). J Petrology 55, 1129-1171. https://doi.org/10.1093/petrology/egu021

Caricchi, L., Annen, C., Blundy, J., Simpson, G., Pinel, V., 2014. Frequency and magnitude of volcanic eruptions controlled by magma injection and buoyancy. Nature Geoscience 7, 126-130. https://doi.org/10.1038/ngeo2041

Cashman, K.V., Sparks, R.S.J., Blundy, J.D., 2017. Vertically extensive and unstable magmatic systems: A unified view of igneous processes. Science 355 , eaag3055. https://doi.org/10.1126/science.aag3055

Coombs, M.L., Gardner, J.E., 2001. Shallow-storage conditions for the rhyolite of the 1912 eruption at Novarupta, Alaska. Geology 29, 775-778. https://doi.org/10.1130/00917613(2001)029<0775:SSCFTR $>2.0$. CO;2

Couch, S., Sparks, R.S.J., Carroll, M.R., 2001. Mineral disequilibrium in lavas explained by convective self-mixing in open magma chambers. Nature 411, 1037-1039. https://doi.org/10.1038/35082540

Druitt, T.H., 2014. New insights into the initiation and venting of the Bronze-Age eruption of Santorini (Greece), from component analysis. Bull Volcanol 76, 794. https://doi.org/10.1007/s00445-0140794-x

Dufek, J., Bergantz, G.W., 2005. Lower Crustal Magma Genesis and Preservation: a Stochastic Framework for the Evaluation of Basalt-Crust Interaction. J Petrology 46, 2167-2195. https://doi.org/10.1093/petrology/egi049

Eichelberger, J.C., Izbekov, P.E., 2000. Eruption of andesite triggered by dyke injection: contrasting cases at Karymsky Volcano, Kamchatka and Mt Katmai, Alaska. Philosophical Transactions of the Royal Society of London. Series A: Mathematical, Physical and Engineering Sciences 358, 14651485 . 
Flaherty, T., Druitt, T.H., Tuffen, H., Higgins, M.D., Costa, F., Cadoux, A., 2018. Multiple timescale constraints for high-flux magma chamber assembly prior to the Late Bronze Age eruption of Santorini (Greece). Contrib Mineral Petrol 173, 75. https://doi.org/10.1007/s00410-018-1490-1

Garg, R., Galvin, J., Li, T., Pannala, S., 2012. Open-source MFIX-DEM software for gas-solids flows: Part I-Verification studies. Powder Technology 220, 122-137.

Girard, G., Stix, J., 2009. Buoyant replenishment in silicic magma reservoirs: Experimental approach and implications for magma dynamics, crystal mush remobilization, and eruption. J. Geophys. Res. 114, B08203. https://doi.org/10.1029/2008JB005791

Hammer, J.E., Rutherford, M.J., Hildreth, W., 2002. Magma storage prior to the 1912 eruption at Novarupta, Alaska. Contributions to Mineralogy and Petrology 144, 144-162.

Hodge, K.F., Carazzo, G., Jellinek, A.M., 2012. Experimental constraints on the deformation and breakup of injected magma. Earth and Planetary Science Letters 325-326, 52-62. https://doi.org/10.1016/j.eps1.2012.01.031

Holtz, F., Sato, H., Lewis, J., Behrens, H., Nakada, S., 2004. Experimental petrology of the 1991-1995 Unzen dacite, Japan. Part I: phase relations, phase composition and pre-eruptive conditions. Journal of petrology 46, 319-337.

Huber, C., Bachmann, O., Dufek, J., 2011. Thermo-mechanical reactivation of locked crystal mushes: Melting-induced internal fracturing and assimilation processes in magmas. Earth and Planetary Science Letters 304, 443-454. https://doi.org/10.1016/j.eps1.2011.02.022

Huppert, H.E., Sparks, R.S.J., Whitehead, J.A., Hallworth, M.A., 1986. Replenishment of magma chambers by light inputs. Journal of Geophysical Research: Solid Earth 6113-6122. https://doi.org/10.1029/JB091iB06p06113@10.1002/(ISSN)2169-9356.OPENSYS1

Jellinek, A.M., Kerr, R.C., 1999. Mixing and compositional stratification produced by natural convection: 2. Applications to the differentiation of basaltic and silicic magma chambers and komatiite lava flows. Journal of Geophysical Research: Solid Earth 104, 7203-7218. https://doi.org/10.1029/1998JB900117

Karakas, O., Degruyter, W., Bachmann, O., Dufek, J., 2017. Lifetime and size of shallow magma bodies controlled by crustal-scale magmatism. Nature Geoscience 10, 446-450. https://doi.org/10.1038/ngeo2959

Koyaguchi, T., Kaneko, K., 2000. Thermal evolution of silicic magma chambers after basalt replenishments. Earth and Environmental Science Transactions of The Royal Society of Edinburgh 91, 47-60. https://doi.org/10.1017/S0263593300007288

Li, T., Garg, R., Galvin, J., Pannala, S., 2012. Open-source MFIX-DEM software for gas-solids flows: Part II-Validation studies. Powder Technology 220, 138-150.

Mandeville, C.W., Carey, S., Sigurdsson, H., 1996. Magma mixing, fractional crystallization and volatile degassing during the 1883 eruption of Krakatau volcano, Indonesia. Journal of Volcanology and Geothermal Research 74, 243-274.

Martin, V.M., Davidson, J., Morgan, D., Jerram, D.A., 2010. Using the Sr isotope compositions of feldspars and glass to distinguish magma system components and dynamics. Geology 38, 539542. https://doi.org/10.1130/G30758.1

Mastin, L.G., 2002. Insights into volcanic conduit flow from an open-source numerical model. Geochemistry, Geophysics, Geosystems 3, 1-18. https://doi.org/10.1029/2001GC000192

McIntire, M.Z., Bergantz George W., Schleicher Jillian M., 2019. On the hydrodynamics of crystal clustering. Philosophical Transactions of the Royal Society A: Mathematical, Physical and Engineering Sciences 377, 20180015. https://doi.org/10.1098/rsta.2018.0015 
Michioka, H., Sumita, 2005. Rayleigh-Taylor instability of a particle packed viscous fluid: Implications for a solidifying magma. Geophysical Research Letters 32. https://doi.org/10.1029/2004GL021827

Nakamura, M., 1995. Continuous mixing of crystal mush and replenished magma in the ongoing Unzen eruption. Geology 23, 807-810.

Pallister, J.S., Hoblitt, R.P., Meeker, G.P., Knight, R.J., Siems, D.F., 1996. Magma mixing at Mount Pinatubo: petrographic and chemical evidence from the 1991 deposits. Fire and mud: eruptions and lahars of Mount Pinatubo, Philippines 687-731.

Parmigiani, A., Huber, C., Bachmann, O., 2014. Mush microphysics and the reactivation of crystal-rich magma reservoirs. Journal of Geophysical Research: Solid Earth 119, 6308-6322. https://doi.org/ 10.1002/2014JB011124

Schleicher, J.M., Bergantz, G.W., 2017. The Mechanics and Temporal Evolution of an Open-system Magmatic Intrusion into a Crystal-rich Magma. J Petrology 58, 1059-1072. https://doi.org/10.1093/petrology/egx045

Schleicher, J.M., Bergantz, G.W., Breidenthal, R.E., Burgisser, A., 2016. Time scales of crystal mixing in magma mushes. Geophysical Research Letters 43, 1543-1550. https://doi.org/10.1002/2015GL067372

Self, S., 1992. Krakatau revisited: The course of events and interpretation of the 1883 eruption. GeoJournal 28, 109-121. https://doi.org/10.1007/BF00177223

Singer, B.S., Costa, F., Herrin, J.S., Hildreth, W., Fierstein, J., 2016. The timing of compositionally-zoned magma reservoirs and mafic 'priming' weeks before the 1912 Novarupta-Katmai rhyolite eruption. Earth and Planetary Science Letters 451, 125-137. https://doi.org/10.1016/j.epsl.2016.07.015

Snyder, D., Tait, S., 1995. Replenishment of magma chambers: comparison of fluid-mechanic experiments with field relations. Contrib Mineral Petrol 122, 230-240. https://doi.org/10.1007/s004100050123

Syamlal, M., 1998. MFIX documentation numerical technique. EG and G Technical Services of West Virginia, Inc., Morgantown, WV (United States).

Syamlal, M., Rogers, W., OBrien, T.J., 1993. MFIX documentation theory guide. USDOE Morgantown Energy Technology Center, WV (United States).

Tomiya, A., Takahashi, E., 1995. Reconstruction of an Evolving Magma Chamber beneath Usu Volcano since the 1663 Eruption. J Petrology 36, 617-636. https://doi.org/10.1093/petrology/36.3.617

Weinberg, R.F., Leitch, A.M., 1998. Mingling in mafic magma chambers replenished by light felsic inputs: fluid dynamical experiments. Earth and Planetary Science Letters 157, 41-56. https://doi.org/10.1016/S0012-821X(98)00025-9

Wiebe, R.A., 2016. Mafic replenishments into floored silicic magma chambers. American Mineralogist 101, 297-310. https://doi.org/10.2138/am-2016-5429 


\section{Non-peer reviewed preprint submitted to EarthArXiv}

559

560 Tables:

\begin{tabular}{|c|c|}
\hline Symbol (unit) & Definition \\
\hline$d_{p}(\mathrm{~m})$ & Particle diameter \\
\hline$E(\mathrm{~Pa})$ & Particle Young modulus \\
\hline $\overrightarrow{F_{C P D}}(\mathrm{~N})$ & Gravity-Pressure-Drag force \\
\hline$\vec{g}\left(\mathrm{~m} \mathrm{~s}^{-2}\right)$ & Gravity acceleration vector \\
\hline$H_{\text {bed }}(\mathrm{m})$ & Particle bed thickness \\
\hline$H_{\text {max }}(\mathrm{m})$ & Intruded layer maximum height above the inlet \\
\hline$H^{*}$ & Dimensionless height of the intruded volume \\
\hline$m_{p}(\mathrm{~kg})$ & Particle mass \\
\hline$P(\mathrm{~Pa})$ & Fluid pressure \\
\hline$R(\mathrm{~m})$ & Intruder batch radius \\
\hline$t^{*}$ & Reduced time \\
\hline$U_{i n j}\left(\mathrm{~m} \mathrm{~s}^{-1}\right)$ & Injection superficial velocity \\
\hline$U_{m f}\left(\mathrm{~m} \mathrm{~s}^{-1}\right)$ & Minimum fluidization superficial velocity \\
\hline$U^{*}$ & Dimensionless injection velocity \\
\hline$\vec{v}_{f}\left(\mathrm{~m} \mathrm{~s}^{-1}\right)$ & Fluid velocity vector \\
\hline $\overrightarrow{v_{p}}\left(\mathrm{~m} \mathrm{~s}^{-1}\right)$ & Particle velocity vector \\
\hline$W_{i n j}(\mathrm{~m})$ & Injection width \\
\hline$\rho_{f}\left(\mathrm{~kg} \mathrm{~m}^{-3}\right)$ & Fluid density \\
\hline$\eta$ (Pa s) & Fluid dynamic viscosity \\
\hline$\tau_{v}(\mathrm{~s})$ & Particle viscous response time \\
\hline$\beta\left(\mathrm{kg} \mathrm{s}^{-1}\right)$ & Momentum transfer coefficient \\
\hline$\Delta t(\mathrm{~s})$ & DEM time step \\
\hline$\eta$ (Pa s) & Fluid dynamic viscosity \\
\hline$\eta_{i}$ (Pa s) & Intruder melt dynamic viscosity \\
\hline$\eta_{h}(\mathrm{~Pa} \mathrm{~s})$ & Host melt dynamic viscosity \\
\hline$\eta^{*}$ & Melts dynamic viscosity ratio \\
\hline$\mu$ & Particle friction coefficient \\
\hline$\rho_{h}\left(\mathrm{~kg} \mathrm{~m}^{-3}\right)$ & Host melt density \\
\hline$\rho_{i}\left(\mathrm{~kg} \mathrm{~m}^{-3}\right)$ & Intruder melt density \\
\hline$\rho_{p}\left(\mathrm{~kg} \mathrm{~m}^{-3}\right)$ & Average density of the particles \\
\hline$\rho^{*}$ & Melts reduced buoyancy \\
\hline$\rho_{h}^{*}$ & Melts bulk reduced buoyancy \\
\hline$\sigma$ & Poisson coefficient \\
\hline$\tau_{v}(\mathrm{~s})$ & Particle viscous response time \\
\hline$\Phi$ & Solid volume fraction \\
\hline
\end{tabular}




\section{Non-peer reviewed preprint submitted to EarthArXiv}

Table 1: List of symbols and their meaning

562

Table 2: Parameters kept constant during the parametric study

\begin{tabular}{ll}
\hline Parameter & Value or range \\
\hline$\rho_{p}$ & $3300 \mathrm{~kg} \mathrm{~m}^{-3}$ \\
\hline$d_{p}$ & $4.5-5.5 \mathrm{~mm}$ \\
\hline $\mathrm{Nb}$ crystals & 208495 \\
\hline$H_{\text {bed }}$ & $0.3 \mathrm{~m}$ \\
\hline$W_{\text {inj }}$ & $0.1 \mathrm{~m}$ \\
\hline$\rho_{i}$ & $2500 \mathrm{~kg} \mathrm{~m}^{-3}$ \\
\hline$\eta_{i}$ & $1 \mathrm{~Pa} \mathrm{~s}$ \\
\hline$E$ & $210^{7} \mathrm{~Pa}$ \\
\hline$\sigma$ & 0.32 \\
\hline$\mu$ & 0.3 \\
\hline
\end{tabular}

\begin{tabular}{|c|c|c|c|c|c|c|c|}
\hline Run nb. & $\rho_{h}\left(\mathbf{k g ~ m}^{-3}\right)$ & $\rho_{h}($ host $)\left(\mathrm{kg} \mathrm{m}^{-3}\right)$ & $\rho^{*}$ & $\rho_{h}^{*}$ & $\eta_{h}($ Pa s) & $U_{m f}\left(\mathrm{~m} \mathrm{~s}^{-1}\right)$ & $U_{i n i}\left(\mathbf{m ~ s}^{-1}\right)$ \\
\hline A1 & 2500 & 3012 & 0 & -0.2048 & 1 & $2.95610^{-4}$ & $6.26810^{-3}$ \\
\hline A2 & 2500 & 3012 & 0 & -0.2048 & 5 & $5.91310^{-5}$ & $1.25410^{-3}$ \\
\hline A3 & 2500 & 3012 & 0 & -0.2048 & 10 & $2.95710^{-5}$ & $6.26810^{-4}$ \\
\hline A4 & 2500 & 3012 & 0 & -0.2048 & 50 & $5.91310^{-6}$ & $1.25410^{-4}$ \\
\hline A5 & 2500 & 3012 & 0 & -0.2048 & 100 & $2.95710^{-6}$ & $6.26810^{-5}$ \\
\hline A6 & 2450 & 2994 & 0.02 & -0.1976 & 1 & $3.14110^{-4}$ & $6.66010^{-3}$ \\
\hline A7 & 2450 & 2994 & 0.02 & -0.1976 & 5 & $6.28310^{-5}$ & $1.33210^{-3}$ \\
\hline A8 & 2450 & 2994 & 0.02 & -0.1976 & 10 & $3.14110^{-5}$ & $6.66010^{-4}$ \\
\hline A9 & 2450 & 2994 & 0.02 & -0.1976 & 50 & $6.28310^{-6}$ & $1.33210^{-4}$ \\
\hline A10 & 2450 & 2994 & 0.02 & -0.1976 & 100 & $3.14110^{-6}$ & $6.66010^{-5}$ \\
\hline A11 & 2550 & 3030 & -0.02 & -0.212 & 1 & $2.77210^{-4}$ & $5.87610^{-3}$ \\
\hline A12 & 2550 & 3030 & -0.02 & -0.212 & 5 & $5.54410^{-5}$ & $1.17510^{-3}$ \\
\hline A13 & 2550 & 3030 & -0.02 & -0.212 & 10 & $2.77210^{-5}$ & $5.87610^{-4}$ \\
\hline A14 & 2550 & 3030 & -0.02 & -0.212 & 50 & $5.54410^{-6}$ & $1.17510^{-4}$ \\
\hline A15 & 2550 & 3030 & -0.02 & -0.212 & 100 & $2.77210^{-6}$ & $5.87610^{-5}$ \\
\hline A16 & 2200 & 2904 & 0.12 & -0.1616 & 1 & $4.06510^{-4}$ & $8.61810^{-3}$ \\
\hline A17 & 2200 & 2904 & 0.12 & -0.1616 & 5 & $8.13010^{-5}$ & $1.72410^{-3}$ \\
\hline A18 & 2200 & 2904 & 0.12 & -0.1616 & 10 & $4.06510^{-5}$ & $8.61810^{-4}$ \\
\hline A19 & 2200 & 2904 & 0.12 & -0.1616 & 50 & $8.13010^{-6}$ & $1.72410^{-4}$ \\
\hline A20 & 2200 & 2904 & 0.12 & -0.1616 & 100 & $4.06510^{-6}$ & $8.61810^{-5}$ \\
\hline A21 & 2150 & 2886 & 0.14 & -0.1544 & 1 & $4.25010^{-4}$ & $9.01010^{-3}$ \\
\hline A22 & 2150 & 2886 & 0.14 & -0.1544 & 5 & $8.50010^{-4}$ & $1.80210^{-3}$ \\
\hline
\end{tabular}


Non-peer reviewed preprint submitted to EarthArXiv

\begin{tabular}{|c|c|c|c|c|c|c|c|}
\hline Run nb. & $\rho_{h}\left(\mathbf{k g ~ m}^{-3}\right)$ & $\rho_{h}($ host $)\left(\mathrm{kg} \mathrm{m}^{-3}\right)$ & $\rho^{*}$ & $\rho_{h}^{*}$ & $\eta_{h}$ (Pa s) & $U_{m f}\left(\mathrm{~m} \mathrm{~s}^{-1}\right)$ & $U_{i n j}\left(\mathbf{m ~ s}^{-1}\right)$ \\
\hline A23 & 2150 & 2886 & 0.14 & -0.1544 & 10 & $4.25010^{-5}$ & $9.01010^{-4}$ \\
\hline A24 & 2150 & 2886 & 0.14 & -0.1544 & 50 & $8.50010^{-6}$ & $1.80210^{-4}$ \\
\hline A25 & 2150 & 2886 & 0.14 & -0.1544 & 100 & $4.25010^{-6}$ & $9.01010^{-5}$ \\
\hline B1 & 2150 & 2886 & 0.14 & -0.1544 & 100 & $4.25010^{-6}$ & $4.25010^{-3}$ \\
\hline B2 & 2150 & 2886 & 0.14 & -0.1544 & 100 & $4.25010^{-6}$ & $4.25010^{-2}$ \\
\hline B3 & 2150 & 2886 & 0.14 & -0.1544 & 100 & $4.25010^{-6}$ & $4.25010^{-1}$ \\
\hline B4 & 2150 & 2886 & 0.14 & -0.1544 & 100 & $4.25010^{-6}$ & $4.25010^{0}$ \\
\hline
\end{tabular}

Table 3: List of the simulation performed for this chapter and corresponding variables. 


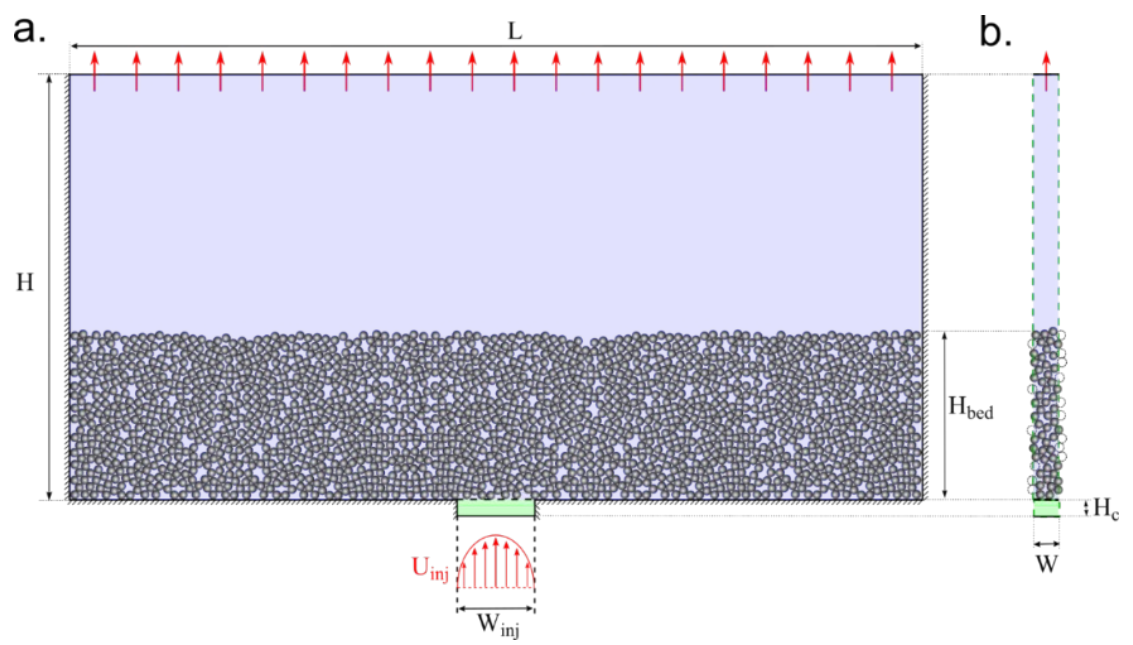

566 Figure 1: Simulations initial condition. [A] The drawing represents the computational domain 567 viewed from the front. The medium is composed by rectangular box, which is fed by a conduit at 568 its based. Particles are settled to generate a particle bed having a thickness $H_{\text {bed }}$. The background 569 colors indicates which fluid is present initially in the computational domain. The blue color 570 corresponds to the host melt and the green color to the intruded melt. The red arrows below the 571 conduit represent the velocity profile of the injected fluid (Poiseuille flow). The arrows atop the 572 domain indicate that the boundary condition is a fixed pressure outflow. The hatched walls 573 indicate non-slip boundary conditions. [B] Side view of the computational domain. The green 574 dashed lines indicate that cyclical boundary conditions are used for these walls. The dotted circles

575 indicate particles overlapping with one of the two cyclical boundary conditions and that are also 576 considered to be present on the opposite side. 


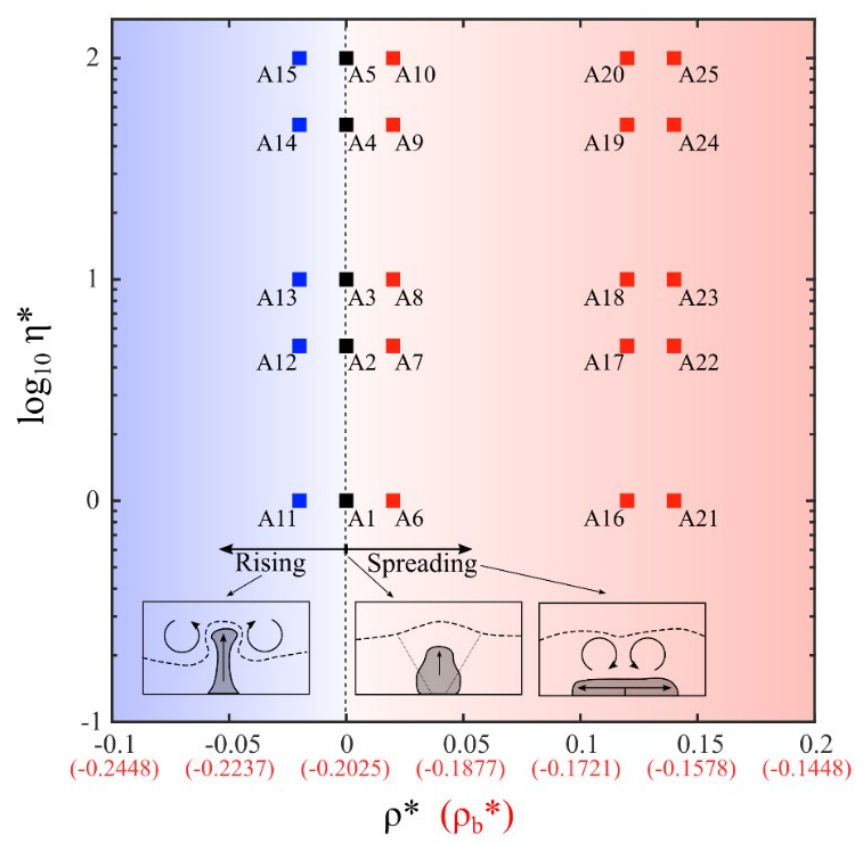

581 Figure 2: Regime diagram of intrusion behavior for $U^{*}=21.2$. The diagram represents the 582 positions of the simulations A1-25 as functions of the reduced buoyancy (abscissa) and viscosity 583 ratios (ordinate). Each square represents a simulation. Square colors depend on the observed 584 regime (blue=rising; black=fluidization; red=lateral spreading). Similarly, the background color 585 interpolates the observed regimes (blue= rising; red=lateral spreading) and the vertical dashed 586 line interpolates where the fluidization is expected to prevail. 


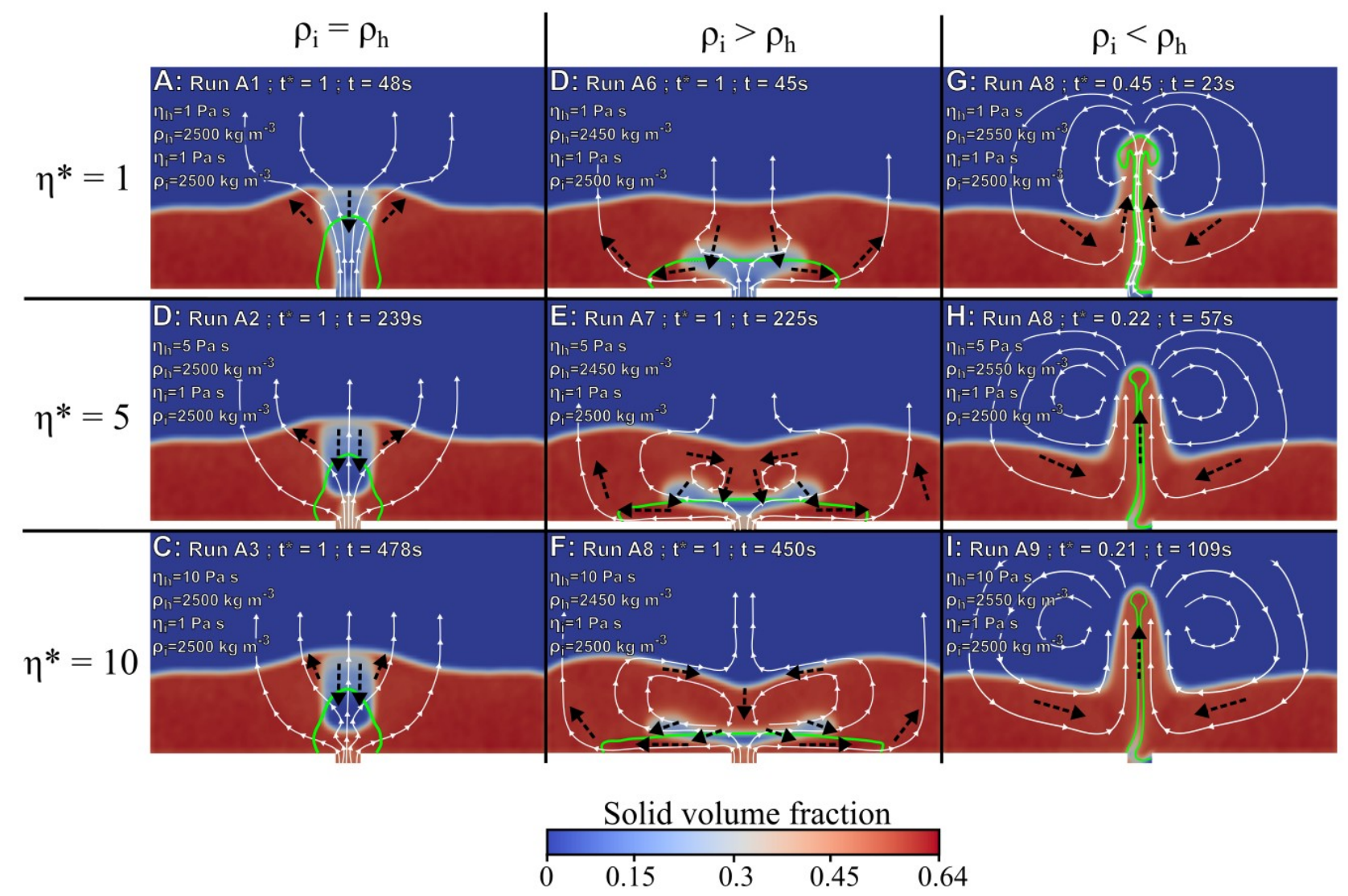

591 Figure 3: Comparison of the effects of buoyancy and viscosity contrasts. Each section represents

592 the advancement of the simulation at $t^{*}=1$ (or when the rising instability is above the particle

593 bed). The injected melt contours are indicated with green curves. The dashed black arrows

594 indicate the presence and direction of granular flows. The thin white curves indicate the fluid

595 streamlines with small arrowheads indicating flow direction. 
Non-peer reviewed preprint submitted to EarthArXiv

596

Preprint submitted to Earth and Planetary Science Letters 


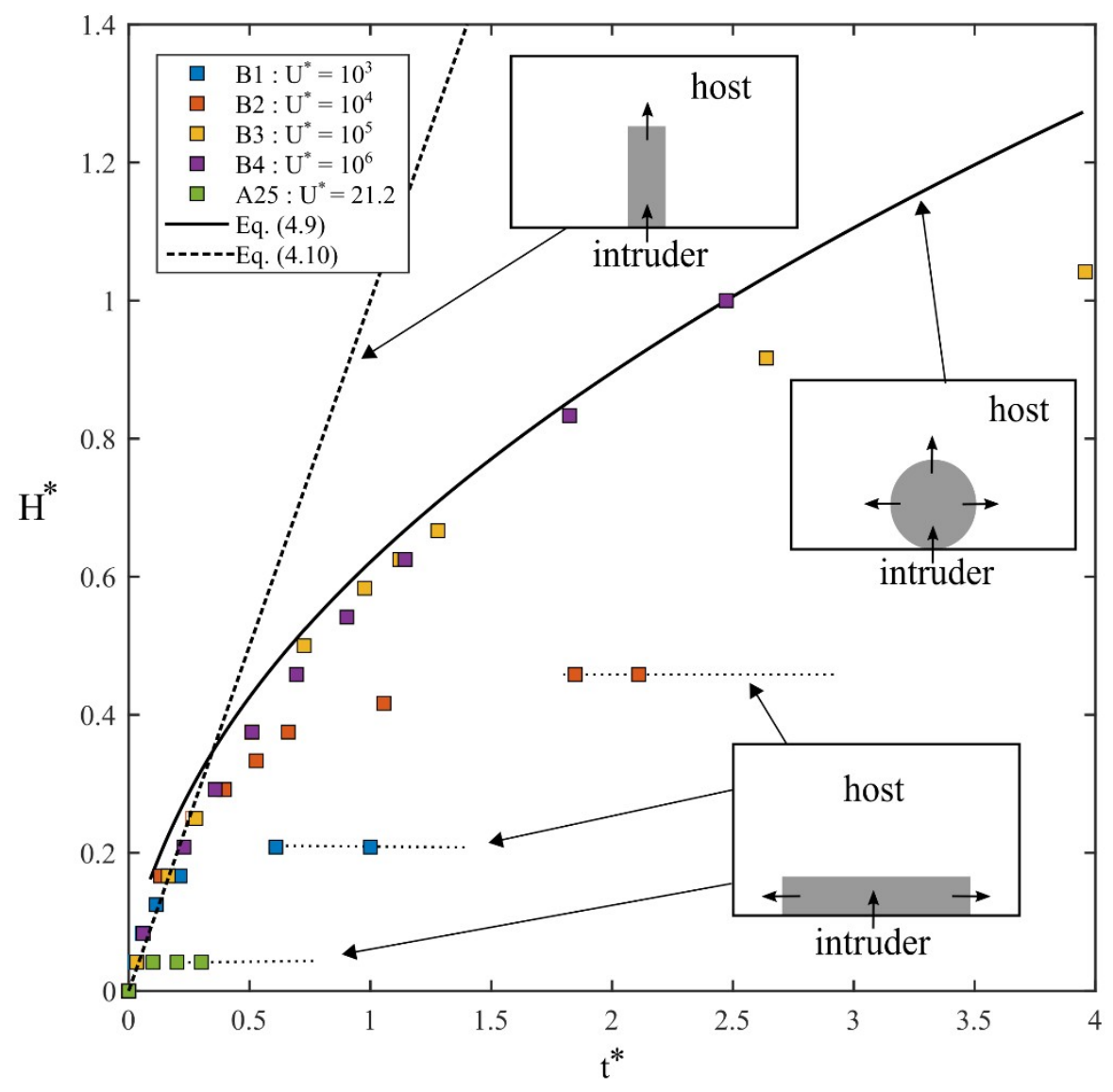

598 Figure 4: Evolution of the height, $H^{*}$, of the intruded volume as a function of the dimensionless 599 time $t^{*}$. Each square represents the height of the top of the intruded volume measured in the 600 simulations. Square colors indicate injection rate. Dashed lines indicate the theoretical intruder 601 front height evolution in the case of vertical propagation (supplementary information 3) The 602 black curve is the theoretical front height for a radial growth, and the horizontal dotted lines 
603 indicate the front height evolution during lateral spreading. The three insets illustrate intrusion 604 behaviors.
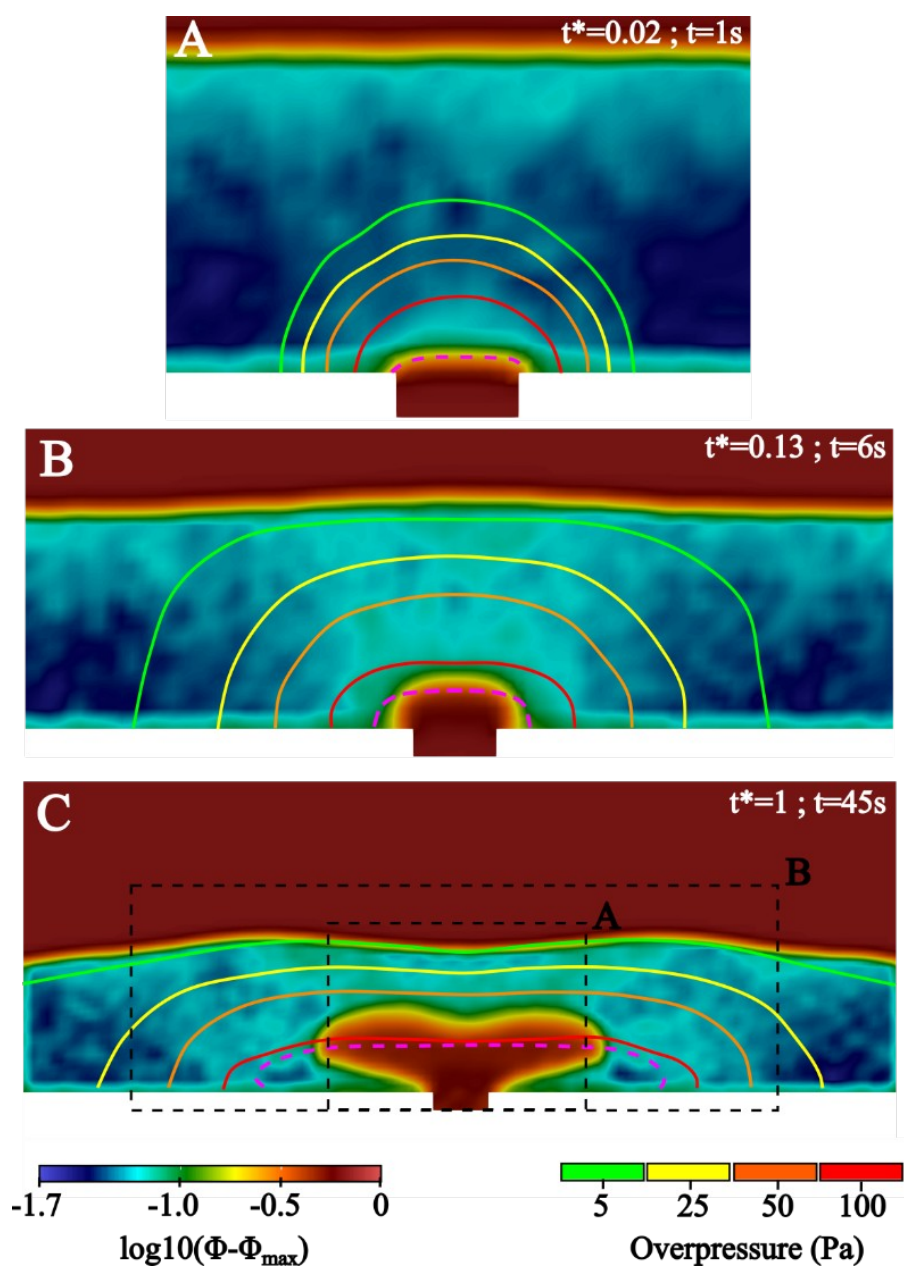

606 Figure 5: Evolution of the pore pressure and crystal volume fraction. On each inset, the color 607 depend on the difference between the local crystal volume fraction, $\Phi$, and the maximum one, $608 \Phi_{\max }\left(\Phi_{\max }=0.64\right)$, in a logarithmic scale. The overpressure respect to the initial hydrostatic 609 pressure field is indicated with contour that corresponds to the isosurfaces where the overpressure 610 are equal to 5, 25, 50, and $100 \mathrm{~Pa}$. The pink dashed curves represent the boundary between the 
611 injected and resident melt. Inset [A] and [B] are captured after 1s and 6s. Both only displayed the 612 portion of the mush layer that present overpressure and dilation. Inset [C] is acquired after $45 \mathrm{~s}$ 613 and cover a slice of the entire computational domain. The two dashed rectangle indicate the 614 extend of insets $[\mathrm{A}]$ and $[\mathrm{B}]$. 

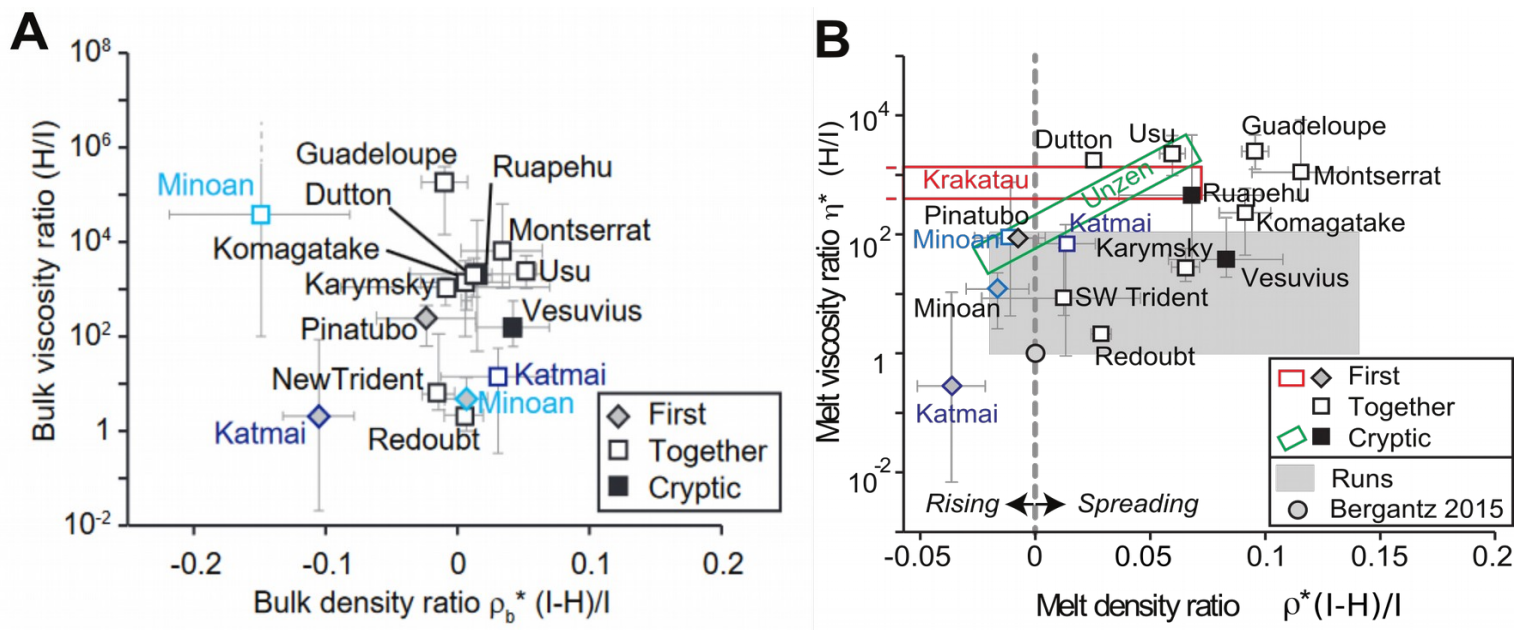

616

617 Figure 6: [A] Ratios of bulk properties for the host and intruder magmas involved in 15 618 eruptions. The bulk viscosity ratio is that of the host over that of the intruder and the bulk density 619 ratio is that of the difference between the intruder and the host over that of the intruder. Eruptions 620 are sorted according to whether the intruder magma was erupted first ("First"), at the same time 621 as (or mixed with) the host ("Together"), or fully mixed with the host ("Cryptic"). [B] Ratios of 622 melt properties for the host and intruder magmas involved in 15 eruptions. The melt viscosity 623 ratio is that of the host over that of the intruder and the melt density ratio is that of the difference 624 between the intruder and the host over that of the intruder. Eruptions are sorted according to 625 whether the intruder magma was erupted first ("First"), at the same time as (or mixed with) the 626 host ("Together"), or fully mixed with the host ("Cryptic"). The gray area covers the runs done in 627 this study and the cross marks the parameters used in the numerical study of Bergantz et al. 628 (2015). See text for details regarding the special cases of Unzen and Krakatau.

629

630 
Non-peer reviewed preprint submitted to EarthArXiv

632

633

634

635

Supplementary Information 1:

This Supplementary Information includes two tables summarizing the equation system solved in our numerical simulations (Tables S1-S2).

Table S1: List of the equations implemented in the CFD-DEM model

\begin{tabular}{|c|c|c|}
\hline Equation names & Equations & Ref. \\
\hline Mass conservation & $\frac{\partial \varepsilon_{f}}{\partial t}+\nabla \cdot\left(\varepsilon_{f} \vec{v}_{f}\right)=0$ & 1 \\
\hline Momentum conservation & $\rho_{f}\left(\frac{\partial}{\partial t}\left(\varepsilon_{f} \vec{v}_{f}\right)+\nabla \cdot\left(\varepsilon_{f} \vec{v}_{f} \otimes \vec{v}_{f}\right)\right)=\nabla \cdot\left(\sigma_{f}\right)+\varepsilon_{f} \rho_{f} \vec{g}+\vec{I}_{f}$ & 1 \\
\hline Stress tensor & $\dot{\sigma}_{f}=P_{f} \delta_{i j}+\frac{2}{3} \eta_{f} \operatorname{tr}\left(\dot{\epsilon}_{f}\right) \delta_{i j}+2 \eta_{f} \dot{\epsilon}_{f}$ & 1 \\
\hline Euler velocity integration & $\vec{v}_{p}^{(k)}(t+\Delta t)=\vec{v}_{p}^{(k)}(t)+\Delta t \frac{\overrightarrow{F_{G P D}}(t)(t)+\sum_{l=1}^{N_{l}^{k}}\left(\vec{F}_{C}^{N(k, l)}(t)+{\overrightarrow{F_{C}^{T}}}^{(k, l)}(t)\right)}{m^{(k)}}$ & $\begin{array}{l}\text { Eq. } \\
(4.4)\end{array}$ \\
\hline $\begin{array}{l}\text { Euler displacement } \\
\text { integration }\end{array}$ & $\vec{X}_{p}^{(k)}(t+\Delta t)=\vec{X}_{p}^{(k)}(t)+\Delta t \vec{v}_{p}^{(k)}(t+\Delta t)$ & 2 \\
\hline Euler rotation integration & $\vec{\omega}_{p}^{(k)}(t+\Delta t)=\vec{\omega}_{p}^{(k)}(t)+\Delta t \frac{\sum_{l=1}^{N_{l}^{k}}\left(\vec{T}_{C}^{(k, l)}+\vec{T}_{L}^{(k, l)}(t)\right)}{I^{(k)}}$ & 2 \\
\hline Normal contact force & $\overrightarrow{F_{c}^{N}(i, j)}(t)=\left(-k_{n}^{(i, j)}(t) \delta_{n}^{(i, j)}(t)+\eta_{n}^{(i, j)}(t) \Delta{\overrightarrow{V_{p}^{N}}}_{p}^{(i, j)}(t)\right) \vec{n}_{i j}$ & 25 \\
\hline Tangential contact force & $\overrightarrow{F_{c}^{T}(i, j)}(t)=-k_{t}^{(i, j)}(t) \delta_{t}^{(i, j)}(t)+\eta_{t}^{(i, j)}(t) \overrightarrow{\Delta V_{p}^{T}(i, j)}(t)$ & 25 \\
\hline Collisional torque & $\vec{T}_{c}^{(i, j)}(t)=\frac{d_{p}^{(i)}-\delta_{n}^{(i, j)}(t)}{2} \vec{F}_{c}^{T}(i, j)(t) ; \vec{T}_{c}^{(j, i)}(t)=\frac{d_{p}^{(j)}-\delta_{n}^{(i, j)}(t)}{2} \vec{F}_{c}^{T}(i, j)(t)$ & 2 \\
\hline $\begin{array}{l}\text { normal spring (Hertzian } \\
\text { model) }\end{array}$ & $k_{n}^{(i, j)}(t)=\frac{4}{3} \frac{E^{(i)} E^{(j)} \sqrt{R_{e f f}^{(i, j)}}}{E^{(j)}\left(1-\sigma^{(i \mid 2)}+E^{(i)}\left(1-\sigma^{(j) 2}\right)\right.} \delta_{n}^{(i, j) \frac{1}{2}}(t)$ & 2 \\
\hline $\begin{array}{l}\text { tangential spring } \\
\text { (Hertzian model) }\end{array}$ & $k_{t}^{(i, j)}(t)=\frac{16}{3} \frac{G^{(i)} G^{(j)} \sqrt{R_{e f f}^{(i, j)}}}{G^{(j)}\left(2-\sigma^{(i)}\right)+G^{(i)}\left(2-\sigma^{(j))}\right.} \delta_{t}^{\left(i, j \frac{1}{2}\right.}(t)$ & 2 \\
\hline
\end{tabular}

Preprint submitted to Earth and Planetary Science Letters 
Non-peer reviewed preprint submitted to EarthArXiv

\begin{tabular}{|c|c|c|}
\hline Equation names & Equations & Ref. \\
\hline Elastic modulus & $G=\frac{E}{2(1+\sigma)}$ & 2 \\
\hline $\begin{array}{l}\text { Normal damping } \\
\text { coefficient }\end{array}$ & $\eta_{n}^{(i, j)}(t)=\frac{2 \sqrt{m_{e f f}^{(i, j)} k_{n}^{(i, j)}(t)}\left|\ln e_{n}\right|}{\sqrt{\pi^{2}+\ln ^{2} e_{n}}} \delta_{n}^{(i, j)}(t)^{\frac{1}{4}}$ & 25 \\
\hline $\begin{array}{l}\text { Tangential damping } \\
\text { coefficient }\end{array}$ & $\eta_{t}^{(i, j)}=\frac{2 \sqrt{\left.m_{e f f}^{(i, j)} k_{t}^{(i, j)} \mid t\right)}\left|\ln e_{t}\right|}{\sqrt{\pi^{2}+\ln ^{2} e_{t}}} \delta_{t}^{(i, j)}(t)^{\frac{1}{4}}$ & 25 \\
\hline effective radius & $R_{e f f}^{(i, j)}=\frac{2\left(d \mid p^{(i)}+d_{p}^{(j)}\right)}{d_{p}^{i \mid} d_{p}^{(j)}}$ & 2 \\
\hline Effective mass & $m_{e f f}^{(i, j)}=\frac{m^{(i)}+m^{(j)}}{m^{(i)} m^{(j)}}$ & 2 \\
\hline $\begin{array}{l}\text { Solids/Fluid momentum } \\
\text { exchange on REV }\end{array}$ & $\vec{I}_{f}(t)=\frac{1}{v_{R E V}} \sum_{k=1}^{N_{k}} \vec{F}_{D}^{(k)}(t) K_{R E V}\left(X_{p}^{(k)}\right)$ & 2 \\
\hline Drag forces (for the fluid) & $\vec{F}_{D}^{(k)}(t)=-\nabla P_{f}(t)\left(\frac{\pi}{6} d_{p}^{(k) 3}\right)+\frac{\beta_{f s}^{(k)}(t)}{\left(1-\varepsilon_{f}(t)\right)}\left(\frac{\pi}{6} d_{p}^{(k) 3}\right)\left(\vec{v}_{f}(t)-\vec{v}_{p}^{(k)}(t)\right)$ & 2 \\
\hline $\begin{array}{l}\text { Local fluid/solid } \\
\text { momentum transfer }\end{array}$ & $\beta_{f s}^{(k)}(t)=\left\{\begin{array}{c}\frac{3}{4} C_{D}^{(k)}(t) \frac{\rho_{f} \varepsilon_{f}(t)\left(1-\varepsilon_{f}\right)\left\|\vec{v}_{f}-\vec{v}_{s}^{(k)}\right\|}{d_{p}^{(k)}} \varepsilon_{f}^{-2.65} \varepsilon_{f} \geq 0.8 \\
\frac{150\left(1-\varepsilon_{f}(t)\right)^{2} \eta_{f}}{\varepsilon_{f}(t) d_{p}^{(k)}}+\frac{1.75 \rho_{f}\left(1-\varepsilon_{f}(t)\right)\left\|\vec{v}_{f}(t)-\vec{v}_{s}^{(k)}(t)\right\|}{d_{p}^{(k)}} \varepsilon_{f}\end{array}\right.$ & 34 \\
\hline Drag coefficient & $C_{D}^{(k)}(t)=\left\{\begin{array}{c}\frac{24}{R e^{(k)}(t)\left(1+0.15 R e^{(k)}(t)^{0.687}\right)} R e^{(k)}(t)<1000 \\
0.44 R e^{(k)}(t) \geq 1000\end{array}\right.$ & 34 \\
\hline $\begin{array}{l}\text { Particle Gravity-Drag- } \\
\text { Pressure force }\end{array}$ & $\overrightarrow{F_{G P D}}(t)=\frac{m_{p}}{\Delta t}\left(\vec{v}_{f}+\tau_{v}\left(\vec{g}-\frac{\nabla P}{\rho_{p}}\right)-\vec{v}_{p}(t)\right)\left(1-e^{\frac{-\Delta t}{\tau_{v}}}\right)$ & $\begin{array}{l}\text { Eq. } \\
(4.5)\end{array}$ \\
\hline Reynolds number & $R e^{(k)}(t)=\frac{d_{m}^{(k)}\left\|\vec{v}_{f}(t)-\vec{v}_{s}^{(k)}(t)\right\| \rho_{f}}{\eta_{f}}$ & 3 \\
\hline
\end{tabular}

${ }^{1}$ Syamlal et al., (1993)

Preprint submitted to Earth and Planetary Science Letters 
${ }^{2}$ Garg et al., (2010)

638

${ }^{3}$ Benyahia et al., (2012)

639

${ }^{4}$ Gidaspow, (1986)

640

641 Table S2 : Symbols used in Table S1

\begin{tabular}{|c|c|}
\hline Symbol & Definition \\
\hline$C_{D}^{(k)}$ & Drag coefficient of the $k^{\text {th }}$ particle \\
\hline$d_{p}^{(i)}$ & $\mathrm{i}^{\text {th }}$ particle diameter \\
\hline$e_{n}$ & Particle normal restitution coefficient \\
\hline$e_{t}$ & Particle tangential restitution coefficient \\
\hline$E^{(i)}$ & $\mathrm{i}^{\text {th }}$ particle Young modulus \\
\hline$\vec{F}_{C}^{N}(k, l)$ & Normal contact force between $\mathrm{k}^{\text {th }}$ particle and its $\mathrm{t}^{\text {th }}$ neighbor \\
\hline $\overrightarrow{F_{C}^{T}}(k, l)$ & Tangential contact forces between $\mathrm{k}^{\text {th }}$ particle and its $\mathrm{I}^{\text {th }}$ neighbor \\
\hline$\vec{F}_{D}(k)$ & Drag force on $\mathrm{k}^{\text {th }}$ particle \\
\hline$\vec{g}$ & Gravitational vector $\left(\mathrm{m} \mathrm{s}^{-2}\right)$ \\
\hline$G^{(k)}$ & $\mathrm{k}^{\text {th }}$ particle shear moduli \\
\hline$h^{(i, j)}$ & Distance between $\mathrm{i}^{\text {th }}$ and $\mathrm{j}^{\text {th }}$ particles edges \\
\hline$\vec{I}_{f}$ & Fluid-solid momentum exchange \\
\hline$I^{(k)}$ & $\mathrm{k}^{\text {th }}$ particle moment of inertia \\
\hline$K_{R E M}$ & Generic kernel to determine the influence of a particle located at $\vec{X}_{p}^{(k)}$ on the REV \\
\hline$k_{n}^{(i, j)}$ & Normal spring coefficient between $\mathrm{i}^{\text {th }}$ and $\mathrm{j}^{\text {th }}$ particles contact \\
\hline$k_{t}^{(i, j)}$ & Tangential spring coefficient between $\mathrm{i}^{\text {th }}$ and $\mathrm{j}^{\text {th }}$ particles contact \\
\hline$l$ & Neighbors index \\
\hline$m^{(k)}$ & $\mathrm{k}^{\text {th }}$ particle mass \\
\hline$m_{e f f}^{(i, j)}$ & $\mathrm{i}^{\text {th }}$ and $\mathrm{j}^{\text {th }}$ particles effective radius \\
\hline
\end{tabular}




\section{Non-peer reviewed preprint submitted to EarthArXiv}

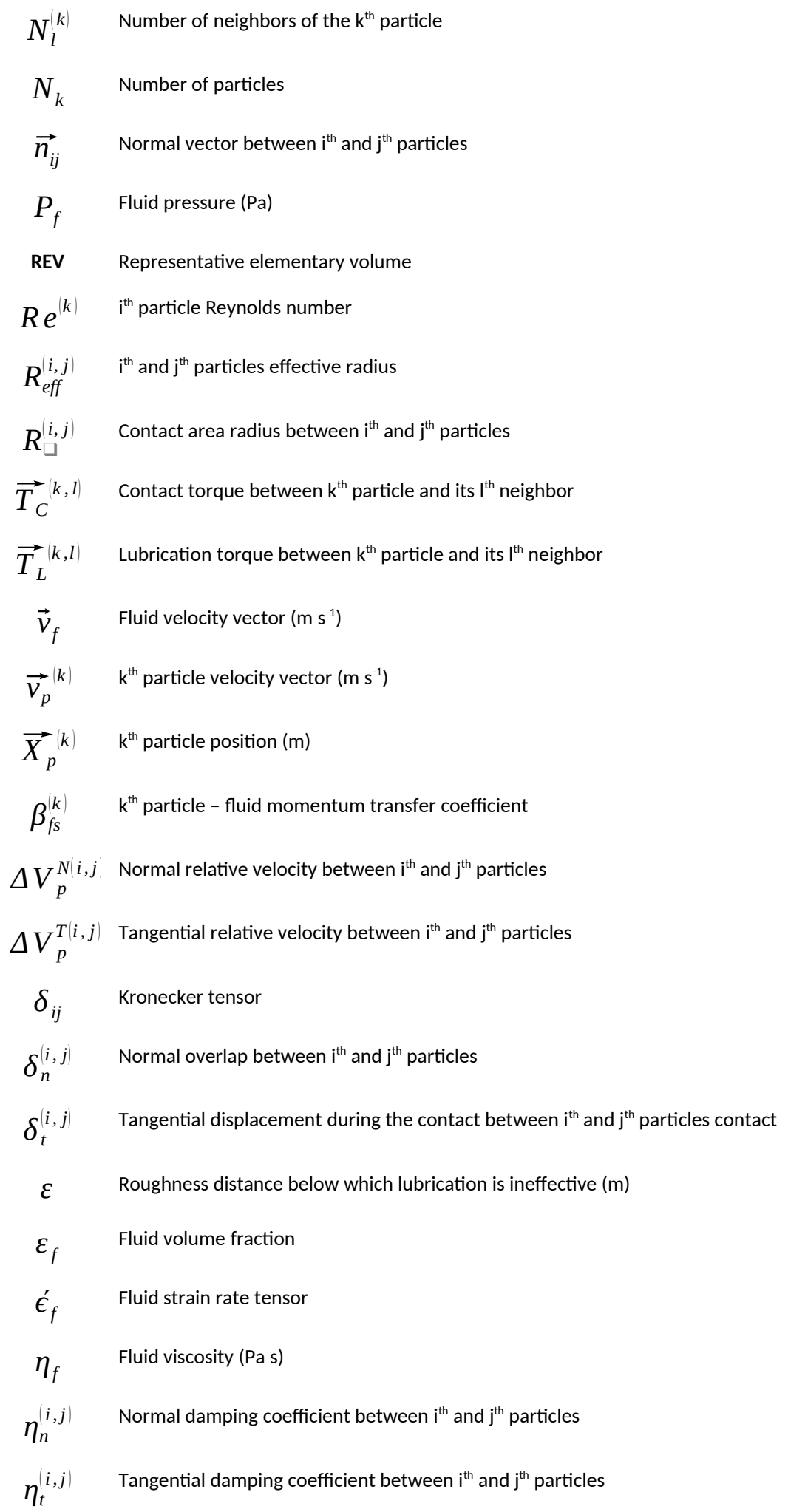




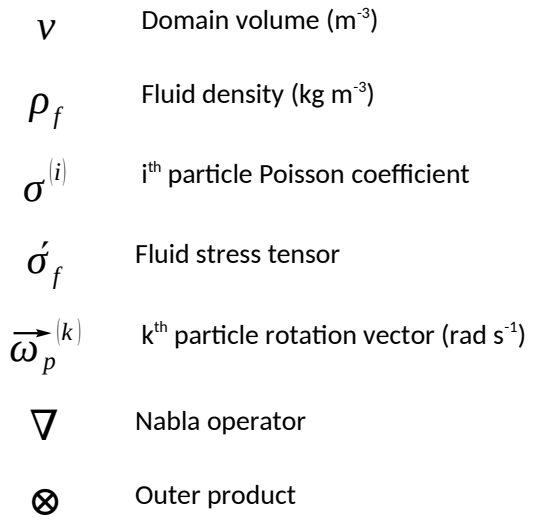

645 This supplementary information presents an updated derivation of the minimum 646 fluidization velocity compared to those used in the literature.

647 The onset of fluidization of a crystal bed occurs when the upward drag force exerted by 648 the injected fluid exceed its net weight. Shi et al. (1984) proposed a formula to predict the 649 minimum fluidization velocity of a random packed bed due to a localized injection of fluid. These 650 authors made the assumption that the fluid velocity is only vertical and uniformly distributed on 651 horizontal cross-sectional area (Fig. S1). The total upward drag force is computed with the 652 Ergun's formula (Ergun, 1952) for a bed fluidized uniformly. Later, Cui et al. (2014) adapted this 653 formula by considering the fluid velocity uniform along a semi-circular cross sectional area. 654 Here, we modify the approach of Cui et al. (2014) to predict the minimum fluidization velocity in 655 the experimental apparatus geometry because the original derivation incorrectly assumed the 656 distance between the injection point and center of the inlet, $r_{0}$, and the boundaries of the 657 integral in their Eq. (13).

658 The total upward drag force applied by the inlet on the particle bed is computed as: 
$659 F_{D}=\int_{r_{0}}^{H+r_{0}}\left(A U_{r}+B U_{r}^{2}\right) S(r) d r$,

660 where $r_{0}$ correspond of the vertical coordinates of the bottom and $H+r_{0}$ is the position of the 661 top of the particle bed. The variable $r$ corresponds to the radial distance from a hypothetic 662 injection point (Fig. S1). $A$ and $B$ are given by Ergun (1952):

$663 \quad A=150 \frac{\phi^{2}}{(1-\phi)^{3}} \frac{\eta_{f}}{d_{p}^{2}}$

$664 \quad B=1.75 \frac{\phi}{(1-\phi)^{3}} \frac{\rho_{f}}{d_{p}}$

$665 S(r)$ represents the area of the curved surface on which the fluid velocity is uniform, and it is 666 computed as a function of $r$ as:

$667 S(r)=2 \alpha\left(r+r_{0}\right) W_{l}$.

$668 U_{r}$ is the fluid velocity at a radial distance $r$. $U_{r}$ may be computed by considering that the 669 injected flux is conserved through the particle bed height, which yields:

$670 Q_{i n j}=U_{r} S(r)$,

671 and, with (S4):

$672 U_{r}=\frac{Q_{i n j}}{2 \alpha\left(r+r_{0}\right) W_{l}}$

673 Substituting Eqs. (S6) and (S4) into Eq. (S1) yields:

$674 F=A Q_{i n j} H_{0}+\frac{B Q_{i n j}^{2}}{2 \alpha W_{l}} \ln \left(\frac{H_{0}+2 r_{0}}{2 r_{0}}\right)$

675 In this geometry, the net weight of the bed, $W$, is given by: 
$676 W=\left[\left(r_{0}+H_{0}\right)^{2} \tan \alpha-\frac{W_{i n j} r_{0}}{2}\right] W_{l}\left(\rho_{p}-\rho_{f}\right) g \phi$.

677 Introducing $r_{0}=W_{i n j} /(2 \tan \alpha)$, the onset of fluidization occurred when $F=W$, which yields:

$678 A Q_{i n j} H_{0}+\frac{B Q_{i n j}^{2}}{2 \alpha W_{l}} \ln \left(\frac{2 \tan \alpha}{W_{i n j}}+1\right)-\left[H_{0}\left(W_{i n j}+H_{0} \tan \alpha\right)\right] W_{l}\left(\rho_{p}-\rho_{f}\right) g \phi=0$

Figure S2 displays comparison of the minimum fluidization velocities computed with 680 formulas from Ergun (1952), Shi et al. (1984), Cui et al., (2014), and Eq. (S9), function of the 681 particle bed height. It shows that Eq (S9) is closer to the result predicted with the formulas from 682 Ergun (1952) and Shi et al. (1984). The incorrect formula derived by Cui et al., (2014) results in 683 the significant overestimations of the minimum fluidization velocity.

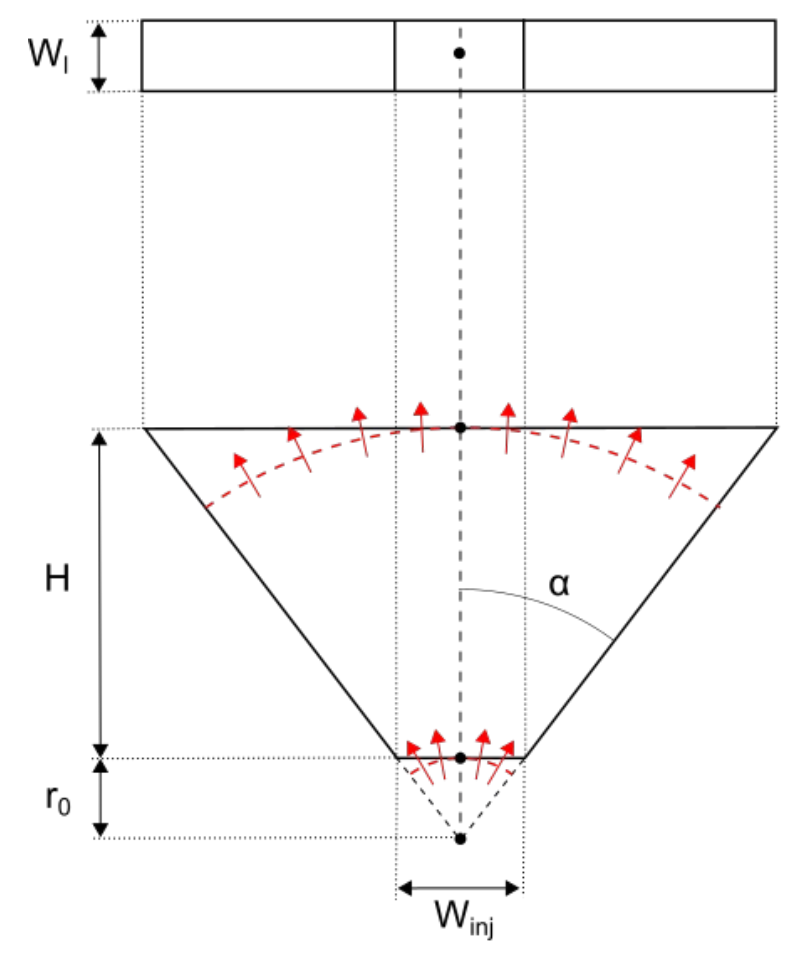




\section{Non-peer reviewed preprint submitted to EarthArXiv}

685 Figure S1: Conceptual framework to derive the minimum fluidization velocity. The top draw is a 686 view from the top. The bottom draw is a front view. On both draws, the thick black lines

687 represent the boundaries of the volume of the particle bed, which is fluidized. The red dashed 688 curves indicate the cross sectional areas where the magnitude of the fluid velocity is uniform.

689 The arrows represent the direction of the fluid flow. The black dots represent the positions of 690 the theoretical injections point and intersections between the cross sectional areas where the 691 fluid velocity is uniform and the vertical boundary of the fluidized particle bed.

692

693

694

695

696

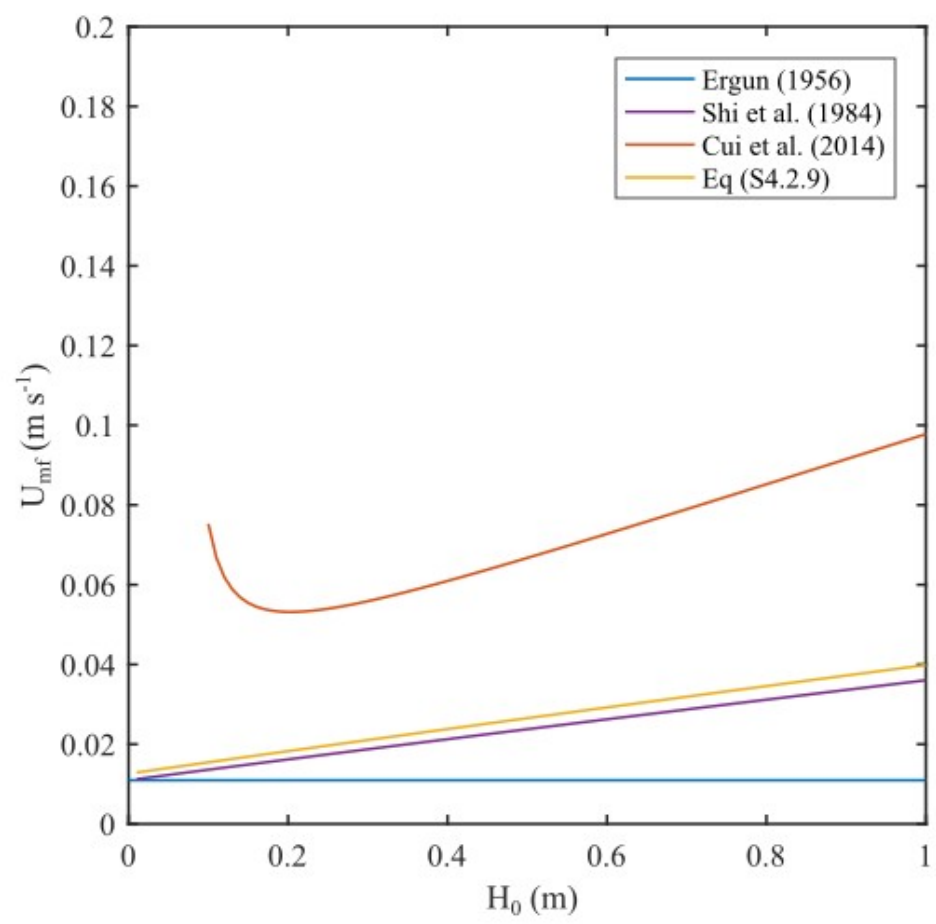

Preprint submitted to Earth and Planetary Science Letters 


\section{Non-peer reviewed preprint submitted to EarthArXiv}

697 Figure S2: Comparison of the minimum fluidization velocities function of the initial particle bed 698 height. The curves represent the minimum fluidization velocities derived by authors and the one 699 given here.

700

701

Preprint submitted to Earth and Planetary Science Letters 
702

703

704

705

706

707

708

$709 H^{*}=t^{*}$.

710

711

712

713

714

715

716

717 The area $A$ depends on injection velocity and time. The area $A_{\text {tot }}$ may be expressed using the sphere radius $R$. Replacing $A$ and $A_{\text {tot }}$ in equation (S11) and rearranging yields:

$719 \pi R^{2}=W_{i n j} H_{b e d} t^{*}+A_{B}$.

The area B may be approximated with a good accuracy as (Harris and Stöcker, 1998, pp 92-93):

$721 \quad A_{B} \approx \frac{2}{3} W_{i n j} h+\frac{h^{3}}{2 W_{i n j}}$.

Inserting Eq. (S13) in Eq. (S12) gives: 


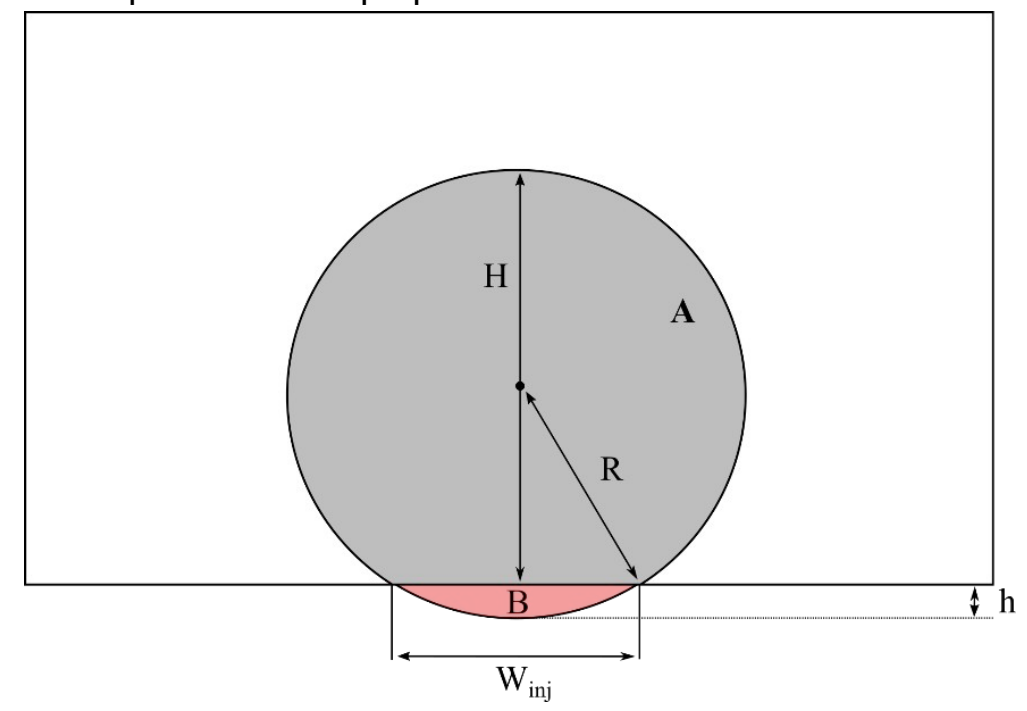

$7230=W_{i n j} H_{b e d} t^{*}+\frac{2}{3} W_{i n j} h+\frac{h^{3}}{2 W_{i n j}}-\pi R^{2}$.

724 Equation (S14) contains two unknowns, $R$ and $h$, which can be related to each other tanks to 725 geometry:

$726 \quad 0=\frac{W_{i n j}^{2}}{4}+(R-h)^{2}-R^{2}$

727 Using that $H=2 R-h, H_{\max }$ may be computed as a function of $t^{*}$ by solving Equations (S14-S15).

728

729

730

731

732

733

734

Preprint submitted to Earth and Planetary Science Letters 
Non-peer reviewed preprint submitted to EarthArXiv

735

Figure S3: Schematics of the geometrical setup. The drawing represents a section 736 perpendicular to the intrusion. The area covered by the injected melt is in gray and the area 
Non-peer reviewed preprint submitted to EarthArXiv

\section{Supplementary information 4:}

This supplementary figures displays the magnitude of the vorticity.

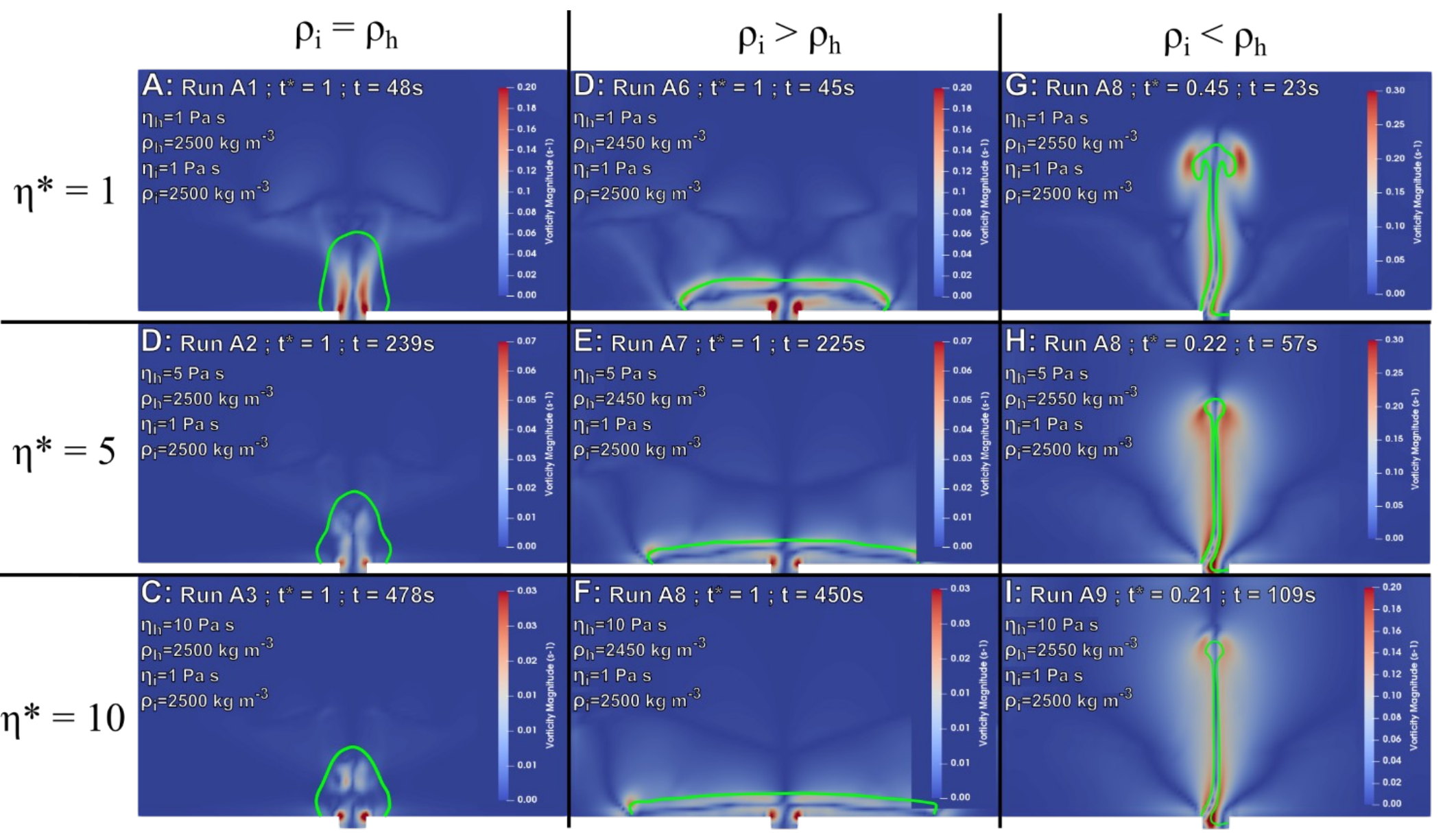


Non-peer reviewed preprint submitted to EarthArXiv

739 Figure S4: Magnitude of the vorticity. Simulations correspond to the ones represented in Fig. 7403 for the same time steps. The green curves indicate the injected melt contour. 
Non-peer reviewed preprint submitted to EarthArXiv

\section{Supplementary information 5:}

This supplementary section present the physical properties of the end members materials

744 involved in the 15 eruption considered in this study. In cases where mixing was so preeminent that

745 only mixed products were erupted (e.g., Unzen), pre-mixing host characteristics, including crystal

746 content, were determined using indirect evidences such as crystal rims in disequilibrium with the

747 surrounding melt. Viscosities and densities of intruder magmas were sometimes directly

748 characterized because they were erupted (e.g., Pinatubo; Pallister et al., 1996) or approximated using

749 petrological inferences (e.g., Usu, where the melt $\mathrm{SiO}_{2}$ content was estimated by Tomiya and

750 Takahashi, 1995, from mixing lines and end-members). The software Conflow (Mastin, 2002) was

751 used to calculate densities and viscosities when necessary.

All host magmas are mushes except one simple case and three complex cases. The Usu

753 reservoir contained a nearly aphyric (2-5 vol.\% crystals) rhyolite prior to the 1663 eruption (Tomiya 754 and Takahashi, 1995). We left this straightforward case in our analysis for completeness; removing it 755 would not affect our results. We treated the next three complex cases separately in our analysis. 756 Krakatau is a compositionally zoned reservoir with a gradient in crystal content ranging from 4-15 757 vol.\% in the felsic (dacitic to rhyodacitic) parts of the reservoir to aphiric in the more mafic (andesite) 758 parts of the reservoir (Mandeville et al., 1996). The second case is the Bronze Age eruption of 759 Santorini volcano known as the Minoan eruption. In one scenario, the reservoir that hosted the 760 Minoan eruption products had $10-20$ vol\% crystals (Cadoux et al., 2014). In others, more complex 761 scenarios have been proposed (Druitt, 2014; Flaherty et al., 2018; Martin et al., 2010). In one, the 762 main rhyodacite would have instead acted as the intruder into an adjacent mushy, mafic reservoir 
763 (Druitt, 2014). We reported these two possibilities. The 1912 eruption at Katmai-Novarupta is also a 764 case where the roles of the intruder and host might be reversed (e.g. Coombs and Gardner, 2001; 765 Eichelberger and Izbekov, 2000; Hammer et al., 2002; Singer et al., 2016). We reported the scenario 766 in which the most crystal-rich components (andesite and dacite) are the hosts and the nearly aphyric 767 rhyolite is the intruder (Eichelberger and Izbekov, 2000), as well as the scenario in which the host is 768 composed of a zoned chamber and the intruder is a basaltic andesite (Singer et al., 2016).

769 There is a last complex case that is analyzed individually although its reservoir unambiguously 770 contained a mush. Two mutually exclusive intrusion scenarios have indeed been proposed to explain 771 the 1991-1995 eruption of Unzen volcano. In both scenarios, the host magma was a phenocryst-rich, 772 low-temperature rhyolite mush and the intruder was a nearly aphyric, high-temperature magma 773 (Holtz et al., 2004; Nakamura, 1995). The composition of the intruder, which left only cryptic 774 indications of its presence such as reverse zoning of the outer rims of hornblende, plagioclase and 775 magnetite (Nakamura, 1995), could have been either andesitic (Holtz et al., 2004), or basaltic 776 (Browne et al., 2006). 
Table S3: Host properties from natural cases (volcano names are followed by the starting year of the eruption). Minerals abbreviations are plagioclase (Plag), clinopyroxene (CPx), orthopyroxene (OPx), pyroxene (Px), and hornblende ( $\mathrm{Hb})$. Only the main mineral phases were taken into account and numbers other minerals. Bulk viscosities were calculated as $\eta_{l}(1-\varphi / 0.6)^{-2.5 \cdot 0.6}$, where $\eta_{l}$ is melt viscosity and $\varphi$ is crystal volume fraction, except for the Minoan scenario 2 where the largest bul viscosity was capped at $10^{10} \mathrm{~Pa}$ s because the higher bound of $\varphi$ is $>0.6$. Abbreviations sat. and usat. mean saturated and undersaturated, respectively. Not used (n.u.) implies that melt densities and/or viscosities were directly given in the reference(s) corresponding to that

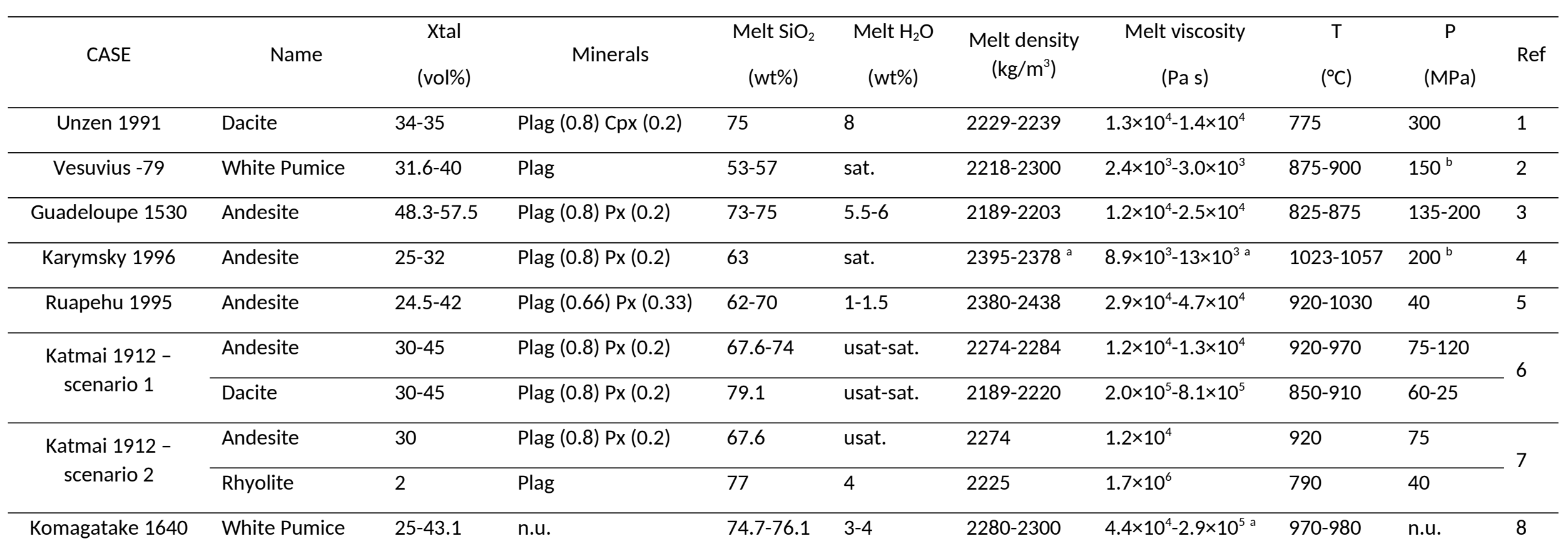


Non-peer reviewed preprint submitted to EarthArXiv

\begin{tabular}{|c|c|c|c|c|c|c|c|c|c|c|}
\hline Montserrat 1995 & Andesite & $35-45$ & Plag & $75-80$ & 4.8 & $2171-2160$ & $3.7 \times 10^{4}-8.4 \times 10^{4}$ & $835-880$ & $105-155$ & 9 \\
\hline Redoubt 1990 & Dacite & $24-32$ & Plag & $78.5-81$ & 4 & $2164-2174$ & $3.4 \times 10^{4}-3.8 \times 10^{4}$ & $840-950$ & 100 & 10 \\
\hline \multirow[t]{2}{*}{ Krakatau 1883} & $\begin{array}{l}\text { White } \\
\text { Rhyodacite }\end{array}$ & $7-15$ & Plag & $70-74$ & 4 & $2220-2400$ & $3.1 \times 10^{4}-3.4 \times 10^{4}$ & $880-890$ & $100-150$ & \multirow[t]{2}{*}{11} \\
\hline & Gray Dacite & $4-12$ & Plag & $66.5-75$ & 4 & $2190-2200$ & $1.3 \times 10^{4}-1.4 \times 10^{4}$ & $890-913$ & $100-150$ & \\
\hline $\begin{array}{l}\text { Minoan - } \\
\text { scenario } 1\end{array}$ & Rhyodacite & $10-20$ & Plag & $73.5-74$ & $5-6$ & $2222-2173$ & $1.7 \times 10^{4}-1.4 \times 10^{5}$ & $845-860$ & $200-250$ & 12 \\
\hline $\begin{array}{c}\text { Minoan - scenario } \\
2\end{array}$ & Andesite & $55-100$ & Plag (0.8) CPx (0.2) & $71-77$ & sat. ${ }^{b}$ & $2213-2231$ & $5.9 \times 10^{5}-1.3 \times 10^{7}$ & $700-820$ & 50 & 13 \\
\hline SW Trident 1953 & Dacite & $37-39$ & Plag (0.8) Px (0.2) & 75 & 3.6 & $2190-2200$ & $4.5 \times 10^{4}-4.9 \times 10^{4}$ & 890 & 90 & 14 \\
\hline Dutton 1989 & Dacite & 35 & Plag (0.8) OPx (0.2) & 78 & sat. & 2481-2491 & $1.4 \times 10^{5}-1.5 \times 10^{5}$ & 865 & $200^{b}$ & 15 \\
\hline \multirow{2}{*}{ Pinatubo 1991} & White Pumice & 47 & Plag (0.8) Hb (0.2) & 76 & $6-6.5$ & 2166 & $5.4 \times 10^{4}$ & $750-800$ & $155-200$ & \multirow{2}{*}{16} \\
\hline & Tan Pumice & $15-26$ & Plag (0.8) Hb (0.2) & 73 & $6-6.5$ & 2194 & $5.6 \times 10^{4}$ & $750-800$ & $155-200$ & \\
\hline Usu 1663 & Silicic magma & $2.6-5.3$ & Plag (0.8) OPx (0.2) & 74 & n.u. & $2210-2224$ & $9.5 \times 10^{4}-2.6 \times 10^{5}$ & $750-800$ & n.u. & 17 \\
\hline
\end{tabular}

$787 \quad{ }^{a}$ Calculated from bulk values given in the reference(s)

$788{ }^{\mathrm{b}}$ Assumed value.

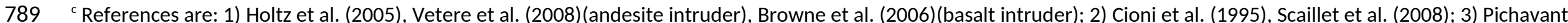
790 et al. (2018); 4) Izbekov et al. (2002), Izbekov et al. (2004), Eichelberger and Izbekov (2000); 5) Nakagawa et al. (1999), Nakagawa et al. (2002), Kilgour et al. (2013); 6)

791 Eichelberger and Izbekov (2000), Coombs and Gardner (2001); 7) Hammer et al. (2002), Singer et al. (2016); 8) Takahashi and Nakagawa (2013); 9) Barclay et al. (1998),

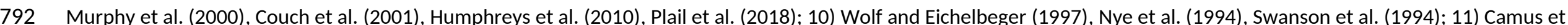

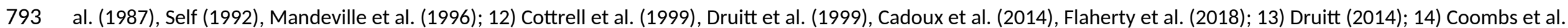

794 (2000), Coombs et al. (2002); 15) Miller et al. (1999); 16) Pallister et al. (1992), Pallister et al. (1996), Bernard et al. (1996); 17) Tomiya and Takahashi (2005). 


\section{Non-peer reviewed preprint submitted to EarthArXiv}

795 Table S4: Intruder properties from natural cases. Minerals abbreviations are plagioclase (Plag), clinopyroxene (CPx),, pyroxene (Px), hornblende (Hb), olivine 796 (Ol), and Augite (Aug). Abbreviations and references are the same as in Table S1.

\begin{tabular}{|c|c|c|c|c|c|c|c|c|c|}
\hline CASE & Name & $\begin{array}{c}\text { Xtal } \\
\text { (vol\%) }\end{array}$ & Minerals & $\begin{array}{c}\text { Melt } \mathrm{SiO}_{2} \\
(w \mathrm{t} \%)\end{array}$ & $\begin{array}{c}\text { Melt } \mathrm{H}_{2} \mathrm{O} \\
(w t \%)\end{array}$ & $\begin{array}{c}\text { Melt density } \\
\qquad\left(\mathrm{kg} / \mathrm{m}^{3}\right)\end{array}$ & $\begin{array}{l}\text { Melt viscosity } \\
\text { (Pa s) }\end{array}$ & $\begin{array}{c}\mathrm{T} \\
\left({ }^{\circ} \mathrm{C}\right)\end{array}$ & $\begin{array}{c}\mathrm{P} \\
(\mathrm{MPa})\end{array}$ \\
\hline \multirow{2}{*}{ Unzen 1991} & Andesite & $0-10$ & Plag $^{b}$ & $62-64$ & 4 & $2184-2194$ & $3.2 \times 10^{2}-3.2 \times 10^{2}$ & $1030-1130$ & 300 \\
\hline & Basalt & $0-5$ & $\mathrm{Ol}$ & 50 & sat. ${ }^{b}$ & $2351-2418$ & $2.3-10$ & $1030-1200^{b}$ & $300^{b}$ \\
\hline Vesuvius -79 & K-rich basalt & $0-20$ & Plag & $50-52$ & usat. & $2485-2441$ & $13-16$ & $1050-1140$ & $150^{b}$ \\
\hline Guadeloupe 1530 & Basalt & $0-12$ & Plag & $50-53$ & $5-6$ & $2436-2420$ & $5.4-9.3$ & $975-1025$ & $200^{b}$ \\
\hline Karymsky 1996 & Basalt & 20 & Plag & 52 & sat. & $2545^{a}$ & $22-54$ & $1080-1115$ & $200^{b}$ \\
\hline Ruapehu 1995 & High-T magma & $0-10$ & Plag $^{b}$ & $54.2-57.7$ & $1-1.5$ & $2530-2640$ & $10-10^{2}$ & $1100^{b}-1200^{b}$ & 40 \\
\hline $\begin{array}{c}\text { Katmai } 1912- \\
\text { scenario } 1\end{array}$ & Rhyolite & 2 & Plag & 77 & 4 & $2225-2172$ & $7.5 \times 10^{3}-1.7 \times 10^{6}$ & $790-850$ & $40-100$ \\
\hline $\begin{array}{c}\text { Katmai } 1912- \\
\text { scenario } 2\end{array}$ & Andesite & $30-45$ & Plag (0.8) Px (0.2) & $67.6-74$ & usat.-sat. & $2274-2284$ & $1.2 \times 10^{4}-1.3 \times 10^{4}$ & $920-970$ & $75-120$ \\
\hline Komagatake 1640 & Basalt & 0 & & 57 & n.u. & $2500^{\mathrm{b}}-2540$ & $5.0 \times 10^{3}-1.0 \times 10^{3 a}$ & 1150 & n.u. \\
\hline Montserrat 1995 & Mafic recharge & $2-4.5$ & Plag & $52-71$ & sat. & $2400-2500$ & $10-10^{2}$ & $975-1196$ & $105-155$ \\
\hline Redoubt 1990 & Andesite & $24-32$ & Plag & $64.5-66$ & 4 & $2228-2238$ & $1.6 \times 10^{4}-1.8 \times 10^{4}$ & $840-950$ & 100 \\
\hline Krakatau 1883 & Basalt & $0-10^{b}$ & Plag $^{b}$ & 61.6 & sat. ${ }^{b}$ & $2355-2363$ & $24-31$ & $984-1011$ & $100-150$ \\
\hline $\begin{array}{l}\text { Minoan - } \\
\text { scenario } 1\end{array}$ & Mafic & $22-40$ & Plag (0.8) CPx (0.2) & $61-63$ & sat. ${ }^{b}$ & $2157-2167$ & $6.1 \times 10^{3}-6.7 \times 10^{3}$ & 880 & 50 \\
\hline $\begin{array}{l}\text { Minoan - } \\
\text { scenario } 2\end{array}$ & Rhyodacite & $10-20$ & Plag & $73.5-74$ & $5-6$ & $2213-2173$ & $1.7 \times 10^{4}-1.4 \times 10^{5}$ & $845-860$ & $200-250$ \\
\hline
\end{tabular}


Non-peer reviewed preprint submitted to EarthArXiv

\begin{tabular}{|c|c|c|c|c|c|c|c|c|c|}
\hline SW Trident 1953 & Andesite & $28-43$ & Plag & $74-63$ & 3.5 & $2150-2295$ & $8.3 \times 10^{2}-10^{4}$ & $990-1010$ & 90 \\
\hline Dutton 1989 & Mafic recharge & $10-30$ & Plag & 74 & sat. & $2546-2556$ & $80-88$ & $1080-1180$ & $200^{b}$ \\
\hline Pinatubo 1991 & Basalt & $19-25$ & $\begin{array}{c}\text { Plag (0.75) } \\
\mathrm{Hb}+\text { Aug+OI }(0.25)\end{array}$ & 73.2 & 2-3 usat. & 2159-2169 & $6.1 \times 10^{2}-6.7 \times 10^{2}$ & 1250 & 250 \\
\hline Usu 1663 & Mafic & $0-1$ & Plag & 54 & n.u. & $2351-2364$ & $57-98$ & $1000-1050$ & n.u. \\
\hline
\end{tabular}

$797{ }^{a}$ Calculated from bulk values given in the reference(s).

$798{ }^{\mathrm{b}}$ Assumed value. 
Non-peer reviewed preprint submitted to EarthArXiv

\section{Supplementary references:}

800

801

802

803

804

805

806

807

808

809

810

811

812

813

814

815

816

817

818

819

820

821

822

823

824

825

826

827

828

829

830

831

832

833

834

835

836

837

838

839

840

841

842

843

844

845

846

847

Barclay, J., Rutherford, M.J., Carroll, M.R., Murphy, M.D., Devine, J.D., Gardner, J., Sparks, R.S.J., 1998. Experimental phase equilibria constraints on pre-eruptive storage conditions of the Soufriere Hills magma. Geophys. Res. Lett. 25, 3437-3440.

Benyahia, S., Syamlal, M., O'Brien, T.J., 2012. Summary of MFIX equations 2012-1. URL Httpsmfix Netl Doe GovdocumentationMFIXEquations2012-1 Pdf.

Bernard, A., Knittel, U., Weber, B., Weis, D., Albrecht, A., Hattori, K., Klein, J., Oles, D., 1996. Petrology and geochemistry of the 1991 eruption products of Mount Pinatubo (Luzon, Philippines) 1126.

Browne, B.L., Eichelberger, J.C., Patino, L.C., Vogel, T.A., Dehn, J., Uto, K., Hoshizumi, H., 2006. Generation of Porphyritic and Equigranular Mafic Enclaves During Magma Recharge Events at Unzen Volcano, Japan. J. Petrol. 47, 301-328. https://doi.org/10.1093/petrology/egi076

Cadoux, A., Scaillet, B., Druitt, T.H., Deloule, E., 2014. Magma Storage Conditions of Large Plinian Eruptions of Santorini Volcano (Greece). J. Petrol. 55, 1129-1171. https://doi.org/10.1093/petrology/egu021

Camus, G., Gourgaud, A., Vincent, P.M., 1987. Petrologic evolution of Krakatau (Indonesia): Implications for a future activity. J. Volcanol. Geotherm. Res. 33, 299-316. https://doi.org/10.1016/0377-0273(87)90020-5

Cioni, R., Civetta, L., Marianelli, P., Metrich, N., Santacroce, R., Sbrana, A., 1995. Compositional layering and syneruptive mixing of a periodically refilled shallow magma chamber: the AD 79 Plinian eruption of Vesuvius. J. Petrol. 36, 739-776.

Coombs, M.L., Eichelbeger, J.C., Rutherford, M.J., 2000. Magma storage and mixing conditions for the 1953-74 eruptions of Southwest Trident volcano, Katmai National Park, Alaska. Contrib. Mineral. Petrlogy 140, 99118.

Coombs, M.L., Eichelberger, J.C., Rutherford, M.J., 2002. Experimental and textural constraints on mafic enclave formation in volcanic rocks. J. Volcanol. Geotherm. Res. 119, 125-144.

Coombs, M.L., Gardner, J.E., 2001. Shallow-storage conditions for the rhyolite of the 1912 eruption at Novarupta, Alaska. Geology 29, 775-778.

Cottrell, E., Gardner, J.E., Rutherford, M.J., 1999. Petrologic and experimental evidence for the movement and heating of the pre-eruptive Minoan rhyodacite (Santorini, Greece). Contrib. Mineral. Petrol. 135, 315331.

Couch, S., Sparks, R.S.J., Carroll, M.R., 2001. Mineral disequilibrium in lavas explained by convective self-mixing in open magma chambers. Nature 411, 1037-1039.

Cui, X., Li, J., Chan, A., Chapman, D., 2014. Coupled DEM-LBM simulation of internal fluidisation induced by a leaking pipe. Powder Technol. 254, 299-306. https://doi.org/10.1016/j.powtec.2014.01.048

Druitt, T.H., 2014. New insights into the initiation and venting of the Bronze-Age eruption of Santorini (Greece), from component analysis. Bull. Volcanol. 76, 794. https://doi.org/10.1007/s00445-014-0794-x

Druitt, T.H., Edwards, L., Mellors, R.M., Pyle, D.M., Sparks, R.S.J., Lanphere, M., Davies, M., Barreirio, B., 1999. Santorini Volcano. Geol. Soc. Mem. 19, 165.

Eichelberger, J.C., Izbekov, P.E., 2000. Eruption of andesite triggered by dyke injection: contrasting cases at Karymsky Volcano, Kamchatka and Mt Katmai, Alaska. Philos. Trans. RS Lond. A358, 1465-1485.

Ergun, S., 1952. Fluid flow through packed columns. Chem Eng Prog 48, 89-94.

Flaherty, T., Druitt, T.H., Tuffen, H., Higgins, M.D., Costa, F., Cadoux, A., 2018. Multiple timescale constraints for high-flux magma chamber assembly prior to the Late Bronze Age eruption of Santorini (Greece). Contrib. Mineral. Petrol. 173, 75. https://doi.org/10.1007/s00410-018-1490-1

Garg, R., Galvin, J., Li, T., Pannala, S., 2010. Documentation of open-source MFIX-DEM software for gas-solids flows. URL Httpsmfix Netl Doe Govdocumentationdemdoc2012-1 PdfAccessed 31 March 2014.

Gidaspow, D., 1986. Hydrodynamics of Fiuidizatlon and Heat Transfer: Supercomputer Modeling. Appl. Mech. Rev. 39, 1-23. https://doi.org/10.1115/1.3143702

Hammer, J.E., Rutherford, M.J., Hildreth, W., 2002. Magma storage prior to the 1912 eruption at Novarupta, Alaska. Contrib. Mineral. Petrol. 144, 144-162. 


\section{Non-peer reviewed preprint submitted to EarthArXiv}

Holtz, F., Sato, H., Lewis, J., Behrens, H., Nakada, S., 2005. Experimental petrology of the 1991-1995 Unzen dacite, Japan. Part I. Phase relations, phase composition and pre-eruptive conditions. J. Petrol. 46, 319-337.

Humphreys, M.C.S., Edmonds, M., Christopher, T., Hards, V., 2010. Magma hybridisation and diffusive exchange recorded in heterogeneous glasses from Soufrière Hills Volcano, Montserrat. Geophys. Res. Lett. 37.

Izbekov, P., Gardner, J.E., Eichelberger, J.C., 2004. Comagmatic granophyre and dacite from Karymsky volcanic center, Kamchatka: experimental constraints for magma storage conditions. J. Volcanol. Geotherm. Res. 131, 1-18.

Izbekov, P.E., Eichelberger, J.C., Patino, L.C., Vogel, T.A., Ivanov, B.V., 2002. Calcic cores of plagioclase phenocrysts in andesite from Karymsky volcano: Evidence for rapid introduction by basaltic replenishment. Geology 30, 799-802. https://doi.org/10.1130/0091-7613(2002)030<0799:CCOPPI>2.0.CO;2

Kilgour, G., Blundy, J., Cashman, K., Mader, H.M., 2013. Small volume andesite magmas and melt-mush interactions at Ruapehu, New Zealand: evidence from melt inclusions. Contrib. Mineral. Petrol. 166, 371392. https://doi.org/10.1007/s00410-013-0880-7

Mandeville, C.W., Carey, S., Sigurdsson, H., 1996. Magma mixing, fractional crystallization and volatile degassing during the 1883 eruption of Krakatau volcano, Indonesia. J. Volcanol. Geotherm. Res. 74, 243-274.

Miller, T.P., Chertkoff, D.G., Eichelberger, J.C., Coombs, M.L., 1999. Mount Dutton volcano, Alaska: Aleutian arc analog to Unzen volcano, Japan. J. Volcanol. Geotherm. Res. 89, 275-301.

Murphy, M.D., Sparks, R.S.J., Barclay, J., Carroll, M.R., Brewer, T.S., 2000. Remobilization of andesite magma by intrusion of mafic magma at the Soufriere Hills Volcano, Montserrat, West Indies. J. Petrol. 41, 21-42.

Nakagawa, M., Wada, K., Thordarson, T., Wood, C.P., Gamble, J.A., 1999. Petrologic investigations of the 1995 and 1996 eruptions of Ruapehu volcano, New Zealand: formation of discrete and small magma pockets and their intermittent discharge. Bull. Volcanol. 61, 15-31.

Nakagawa, M., Wada, K., Wood, C.P., 2002. Mixed magmas, mush chambers and eruption triggers: Evidence from zoned clinopyroxene phenocrysts in andesitic scoria from the 1995 eruptions of Ruapehu volcano, New Zealand. J. Petrol. 43, 2279-2303.

Nye, C.J., Swanson, S.E., Avery, V.F., Miller, T.P., 1994. Geochemistry of the 1989-1990 eruption of Redoubt volcano: Part I. Whole-rock major- and trace-element chemistry. J. Volcanol. Geotherm. Res. 62, 429-452.

Pallister, J.S., Hoblitt, R.P., Meeker, G.P., Knight, R.J., Siems, D.F., 1996. Magma mixing at Mount Pinatubo: petrographic and chemical evidence from the 1991 deposits. pp. 687-731.

Pallister, J.S., Hoblitt, R.P., Reyes, A.G., 1992. A basalt trigger for the 1991 eruptions of Pinatubo volcano ? Nature 356, 426-428.

Pichavant, M., Poussineau, S., Lesne, P., Solaro, C., Bourdier, J.-L., 2018. Experimental Parametrization of Magma Mixing: Application to the ad 1530 Eruption of La Soufrière, Guadeloupe (Lesser Antilles). J. Petrol. 59, 257-282. https://doi.org/10.1093/petrology/egy030

Plail, M., Edmonds, M., Woods, A.W., Barclay, J., Humphreys, M.C.S., Herd, R.A., Christopher, T., 2018. Mafic enclaves record syn-eruptive basalt intrusion and mixing. Earth Planet. Sci. Lett. 484, 30-40. https://doi.org/10.1016/j.epsl.2017.11.033

Scaillet, B., Pichavant, M., Cioni, R., 2008. Upward migration of Vesuvius magma chamber over the past 20,000 years. Nature 455, 216-220.

Self, S., 1992. Krakatau revisited: The course of events and interpretation of the 1883 eruption. GeoJournal 28, 109-121. https://doi.org/10.1007/BF00177223

Shi, Y.F., Yu, Y.S., Fan, L.T., 1984. Incipient fluidization condition for a tapered fluidized bed. 484-489.

Singer, B.S., Costa, F., Herrin, J.S., Hildreth, W., Fierstein, J., 2016. The timing of compositionally-zoned magma reservoirs and mafic 'priming' weeks before the 1912 Novarupta-Katmai rhyolite eruption. Earth Planet. Sci. Lett. 451, 125-137. https://doi.org/10.1016/j.epsl.2016.07.015

Swanson, S.E., Nye, C.J., Miller, T.P., Avery, V.F., 1994. Geochemistry of the 1989-1990 eruption of Redoubt volcano: Part II. Evidence from mineral and glass chemistry. J. Volcanol. Geotherm. Res. 62, 453-468.

Syamlal, M., Rogers, W., OBrien, T.J., 1993. MFIX documentation theory guide. USDOE Morgantown Energy Technology Center, WV (United States).

Takahashi, R., Nakagawa, M., 2013. Formation of a Compositionally Reverse Zoned Magma Chamber: Petrology of the ad 1640 and 1694 Eruptions of Hokkaido-Komagatake Volcano, Japan. J. Petrol. 54, 815-838. https:// doi.org/10.1093/petrology/egs087 


\section{Non-peer reviewed preprint submitted to EarthArXiv}

900

908

909
Tomiya, A., Takahashi, E., 2005. Evolution of the Magma Chamber beneath Usu Volcano since 1663: a Natural Laboratory for Observing Changing Phenocryst Compositions and Textures. J. Petrol. 46, 2395-2426. https://doi.org/10.1093/petrology/egi057

Vetere, F., Behrens, H., Schuessler, J.A., Holtz, F., Misiti, V., Borchers, L., 2008. Viscosity of andesite melts and its implication for magma mixing prior to Unzen 1991-1995 eruption. J. Volcanol. Geotherm. Res., Scientific drilling at Mount Unzen 175, 208-217. https://doi.org/10.1016/j.jvolgeores.2008.03.028

Wolf, K.J., Eichelbeger, J.C., 1997. Syneruptive mixing, degassing, and crystallization at Redoubt Vocano, eruption of December, 1989 to May 1990. J. Volcanol. Geotherm. Res. 75, 19-37. 